\title{
A large-sample investigation into uncertain climate change impacts on high flows across Great Britain
}

\author{
Rosanna A Lane ${ }^{1,2}$, Gemma Coxon ${ }^{1,3}$, Jim Freer ${ }^{1,3,4}$, Jan Seibert ${ }^{5}$, Thorsten Wagener ${ }^{3,6,7}$
}

$5 \quad{ }^{1}$ School of Geographical Sciences, University of Bristol, Bristol, BS8 1SS, UK

${ }^{2}$ Currently at: UK Centre for Ecology \& Hydrology, Wallingford, OX10 8BB, UK

${ }^{3}$ Cabot Institute, University of Bristol, Bristol, BS8 1UJ, UK

${ }^{4}$ University of Saskatchewan, Centre for Hydrology, Canmore, Alberta, T1W 3G1, CANADA

${ }^{5}$ Department of Geography, University of Zurich, Zurich, Switzerland

$10{ }^{6}$ Department of Civil Engineering, University of Bristol, Bristol, BS8 1TR, UK

${ }^{7}$ Institue of Environmental Science and Geography, University of Potsdam, 14476 Potsdam, Germany

Correspondence to: Rosanna A. Lane (roslan@ceh.ac.uk)

Abstract. Climate change may significantly increase flood risk across Great Britain (GB), but there are large uncertainties in

15 both future climatic changes and how these propagate into changing river flows. Here, the impact of climate change on the magnitude and frequency of high flows is modelled for 346 larger $\left(>144 \mathrm{~km}^{2}\right)$ catchments across GB using the latest UK Climate Projections (UKCP18) and the DECIPHeR hydrological modelling framework. This study provides the first spatially consistent GB projections including both climate ensembles and hydrological model parameter uncertainties.

Generally, results indicated an increase in the magnitude and frequency of high flows (Q10, Q1 and annual maximum) along

20 the west coast of GB in the future (2050-2075), with increases in annual maximum flows of up to 65\% for west Scotland. In contrast, median flows (Q50) were projected to decrease across GB. All flow projections contained large uncertainties, and while the RCMs were the largest source of uncertainty overall, hydrological modelling uncertainties were considerable in east and south-east England. Regional variation in flow projections were found to relate to i) differences in climatic change and ii) catchment conditions during the baseline period as characterised by the runoff coefficient (mean discharge divided by mean precipitation). Importantly, increased heavy-precipitation events (defined by an increase in $99^{\text {th }}$ percentile precipitation) did not always result in increased flood flows for catchments with low runoff coefficients, highlighting the varying factors leading to changes in high flows.

These results provide a national overview of climate change impacts on high flows across GB, which will inform climate change adaptation, while also highlighting the need to account for uncertainty sources when modelling climate change impact on high flows. 


\section{Introduction}

Climate change will likely significantly alter hydrological regimes in many parts of the world, with vast implications for water resource planning and policy (Brown et al., 2015; IPCC, 2014; Wagener et al., 2010). Projections indicate an intensification of the hydrological cycle, with a warmer climate leading to more rain falling in high-intensity events (Eicker et al., 2016; Huntington, 2006; IPCC, 2014; Trenberth, 2011). This increase in the frequency and severity of extreme rainfall events is likely to increase flood risk in many regions. However, the conversion of rainfall to runoff is not straightforward, as changes in river flows result from complex and non-linear interactions between changing precipitation and evapotranspiration, and the influence of basin properties (Arnell, 2011; Laizé and Hannah, 2010; Sawicz et al., 2014). There are also many uncertainties

40 surrounding future climate projections. While climate models show general agreement on rising temperatures and increasing extreme precipitation throughout the $21^{\text {st }}$ century, they differ in the magnitude and spatial patterns of change (Fowler and Ekström, 2009; Met Office, 2019; Nikulin et al., 2011). To guide water-related policy and decision making and to ensure adequate adaptation to future changes in flooding, we therefore need hydrological modelling studies to help understand and quantify climate change impacts on the hydrological regime, and the uncertainties surrounding these projections (Reynard et 45 al., 2017).

Hydrological climate change impact studies often use information from global climate models or regional climate models (e.g., rainfall and temperature projections) to drive hydrological models. Throughout this modelling chain there are many uncertainties, which cascade from one step through to another. These include uncertainties in global climate model (GCM) structure and sub-grid parameterisations, uncertainties in regional climate model (RCM) structure and parameterisations, uncertainties in the chosen downscaling and bias correction techniques, and uncertainties in the selection of hydrological model structures and their parameters (Clark et al., 2016; Kundzewicz et al., 2018). Many studies have attempted to quantify the impact of these uncertainties by using multiple GCMs/RCMs, bias correction techniques, hydrological model structures and/or hydrological model parameter sets and propagating these uncertainties through the modelling chain. However, these studies

55 are often focused on small catchment samples as the large numbers of simulations needed are computationally demanding (e.g., Bosshard et al., 2013; De Niel et al., 2019; Kay et al., 2009; Smith et al., 2014; Wilby \& Harris, 2006). Studies generally agree that modelling of the future climate presents the largest source of uncertainty (Engin et al., 2017; Kay et al., 2009; Meresa and Romanowicz, 2017; De Niel et al., 2019). However, hydrological modelling uncertainties are not negligible. The relative contribution of hydrological modelling uncertainties to total uncertainty has been shown to vary depending on catchment 60 characteristics (Addor et al., 2014) and for different aspects of the flow regime (Meresa and Romanowicz, 2017). Understanding and communicating modelling uncertainties has been widely recognised as important to inform robust decisionmaking (Clark et al., 2016; Reynard et al., 2017). 
Many water-related policy decisions are made at the regional to national scale. For example, England has a national flood and coastal erosion risk management strategy (Environment Agency, 2020b). To inform these regional to national policy decisions, hydrological modelling studies which apply a consistent methodology across a large domain / large sample of catchments are most valuable, as they (i) provide a broad overview of future changes, (ii) provide locally relevant information, in contrast to global impact studies, and (iii) enable direct comparison between catchments to identify regions that will experience the most significant climate change impacts (Watts et al., 2015). Using a large sample of catchments also ensures a more robust evaluation of the relationship between climate change impacts and hydrological response.

Over the last decade, large-scale studies evaluating climate change impacts on hydrology have emerged, facilitated by the increased availability of data and computational resources. For example, Köplin et al. (2014) evaluated the changing seasonality and magnitude of floods for 189 catchments covering Switzerland, Thober et al. (2018) modelled changing river floods across Europe, Wang et al. (2012) evaluated changing water resources using the distributed VIC model across China, and a national grid-based model has been applied to explore climate change impact on floods and droughts across Great Britain (Bell et al., 2007, 2012, 2016; Kay \& Crooks, 2014; Lane \& Kay, in review; Rudd et al., 2019). While the use of a GCM/RCM ensemble to evaluate climate uncertainties has become increasingly common (e.g., Bell et al., 2016; Prudhomme et al., 2012; Rudd et al., 2019), the inclusion of hydrological model parameter uncertainties at the national scale is still rare for Great Britain. A notable exception is Christierson et al. (2012), who modelled the impact of changing climate for 70 catchments across the UK using two different hydrological model structures and ensembles of model parameters. However, this study was based on probabilistic climate projections which were not spatially coherent (i.e., projected variables were not consistent over space, and rainfall and precipitation products were not produced from the same simulation), and therefore did not present possible GB-wide changes but rather individual scenarios for each catchment. Incorporating hydrological model parameter uncertainties is important, as it has been shown that very different projections for future catchment behaviour can be provided by parameter sets with similar performance over a baseline period (Mendoza et al., 2015; Singh et al., 2014). However, there are currently no studies providing spatially coherent projections of future changes in flooding across entire Great Britain, which include both RCM and hydrological model parameter uncertainties.

90 An updated set of national climate projections has recently been released for the UK, UKCP18 (Lowe et al., 2019; Murphy et al., 2018). These have advanced upon previously available national projections (UKCP09) through (1) increased resolution of global climate model from $\sim 300 \mathrm{~km}$ to $\sim 60 \mathrm{~km}$ providing better representation of synoptic-scale weather systems, mountains and coastlines, (2) increased resolution of regional climate model from $25 \mathrm{~km}$ to $12 \mathrm{~km}$, which may improve the representation of extreme precipitation, (3) updated atmosphere model and improved parameterisations of many sub-grid scale processes, 95 and (4) improved representation of dynamical influences on regional climate variability such as improvements in predictions of the winter North Atlantic Oscillation (NAO) (Murphy et al., 2018). Preliminary analysis has shown that probabilistic projections produced as part of UKCP18 result in greater uncertainty ranges than the comparable UKCP09 projections (Kay 
et al., 2020). The UKCP18 projections include a perturbed physics ensemble of regional climate model (RCM) projections at $12 \mathrm{~km}$ resolution, providing 12 possible climate futures varying due to RCM parameter uncertainties. The implications of these projections of future flooding.

This paper aims to explore the impact of the new UKCP18 climate projections for high flows across Great Britain (GB). A climate-hydrological model cascade was employed, with output from an ensemble of 12 RCM projections used to drive a nationally applied hydrological model with 30 distributed parameter fields. The resulting 360 future flow scenarios were analysed to answer the following research questions:

1. What is the range in potential changes to median and higher flows (including median flows (Q50), high flow quantiles (Q10 and Q1), annual maximum flows (AMAX) and number of peaks over threshold) across GB, due to parameter uncertainties in climate and hydrological modelling?

2. How will changes in the magnitude and frequency of high flows vary spatially and by region?

3. What is the relationship between changing climate (precipitation and potential evapotranspiration) and high flow response, and how does this vary by region?

Our study presents the first consistent climate change projections for high flows across GB (i.e., using spatially coherent climate projections) to include both climate model and hydrological model parameter uncertainties. The incorporation of a

115 large sample of catchments also enabled robust and generalisable analysis on the relationship between climate forcing, catchment characteristics and hydrological response, which will be relevant to future studies in GB and elsewhere.

\section{Methods and data}

\subsection{Overview}

120 This paper uses a climate-hydrological modelling chain to assess the implications of the UKCP18 climate projections for river high flows across 346 catchments covering GB (see section 2.2 for catchment selection). An ensemble of 12 spatially coherent regional climate model ( $\mathrm{RCM}$ ) projections are first bias-corrected (see section 2.3), and then used directly as inputs to the DECIPHeR hydrological modelling framework to produce flow projections (see section 2.4). For each RCM ensemble member, DECIPHeR simulations are carried out using 30 nationally consistent hydrological model parameter fields (see section 2.4). The use of 12 RCMs and 30 hydrological model parameter sets results in 360 national simulations, representing uncertainty due to RCM and hydrological model parameterisation.

To explore climate change impacts on high flows, flow metrics were selected to assess median flows (Q50), high flow quantiles (Q10 and Q1), the magnitude of peak flows (AMAX), and the frequency of peak flows (see section 2.5). The skill of the 
130 climate-hydrological modelling chain was first evaluated relative to observed flow metrics, and then changes in flow metrics between the baseline (1985-2010) and future (2050 -2075) periods were evaluated.

\subsection{Catchment selection}

A large sample of 346 catchments covering GB was selected for this study. This sample provides a dense coverage across GB, with catchments in all river basin districts, as shown in Figure 1. Gauging stations were selected from the UK National River

135 Flow Archive (NRFA) Service Level Agreement (SLA) Network (Centre for Ecology and Hydrology, 2016; Dixon et al., 2013). This network of 715 gauges forms a subset of strategically valuable NRFA catchments, where additional validation and quality testing procedures have been carried out (Dixon et al., 2013). As hydrometeorological data were available on $12 \mathrm{~km}$ grids at daily resolution, we chose to exclude catchments that were smaller than $144 \mathrm{~km}^{2}$ (i.e., one RCM grid), because for these small catchments local variation in precipitation could be problematic for the RCM ensemble scale, and for small flashy catchments sub-daily data would be required to capture high flow and peak responses effectively.

\subsection{Climate model data}

Climate scenarios representing changes in precipitation and potential evapotranspiration (PET) were derived from the UKCP18 regional climate projections (Murphy et al., 2018). These comprised a perturbed-physics ensemble of 12 regional climate model simulations, run at 12km resolution with daily output from 1981 to 2080 (Met Office Hadley Centre, 2019). The 12 RCM projections were all driven by the same GCM (GC3.05), and for the RCP8.5 emissions scenario. This GCM has been shown to sample the warmer range of global outcomes (Lowe et al., 2019), and so combined with a single emissions scenario, we only sample the warmer range of possible climate outcomes. A key advantage of this data over other UKCP18 products is that it has full spatial and temporal coherence and therefore allows for the assessment of interactions between changes in precipitation and PET as well as providing a nationally consistent picture of future changes (Met Office, 2020).

While precipitation data were available as an RCM output variable, PET time series needed to be derived from other relevant UKCP18 model outputs. There are many possible approaches to calculating PET from climate model data, with the choice of PET equation shown to impact the subsequent changes in PET over time (Kay \& Davies, 2008; Prudhomme \& Williamson, 2013). Here, PET was calculated to be consistent with the CHESS-PE dataset used for hydrological model parameterisation

155 (Robinson et al., 2015). The CHESS-PE dataset uses the Penman-Monteith equation, calculating PET as a function of air temperature, specific humidity, wind speed, shortwave radiation, longwave radiation, and air pressure. These variables were all available as UKCP18 output apart from air pressure, which was calculated using the integral of the hypsometric equation with modelled temperature as an input (Shuttleworth, 2012)

160 Bias correction of climate model output data is often required for hydrological impact studies due to the occurrence of considerable biases in hydrologically relevant variables (Addor and Seibert, 2014; Cloke et al., 2013; Ning et al., 2012; 
Teutschbein and Seibert, 2012). An analysis of biases in the UKCP18 regional projections identified systematic biases in the model output precipitation and model-derived PET data (see Supplement S1 for more information). For precipitation, RCM biases included overpredictions of mean annual precipitation across GB by up to 50\%, underpredictions of rainfall in wetter areas along the west coast, and an increased number of wet days (an average of around 15\% more rainy days per year than observations). RCMs tend to overpredict the variance in PET, resulting in overestimations of PET in the south-east, where observed PET is high, and underestimations in Scotland as well as an incorrect seasonal variation with overestimations in summer (up to around $+40 \%$ ) and underestimations in winter (up to $-100 \%$ ). A bias correction method was required to reduce these biases in RCM precipitation and PET, so that they were suitable for hydrological modelling.

The choice of bias correction has been shown to impact the magnitude and spread of projected changes in flood-producing flows (Cloke et al., 2013; Smith et al., 2014), and should, therefore, be carefully considered. Techniques to directly adjust RCM simulations range from relatively simple linear scaling to more complex approaches such as quantile mapping (Teutschbein and Seibert, 2012). The delta change method, which modifies historical time series based on RCM-simulated changes, is commonly applied (e.g., Veijalainen et al., 2010). However, this method cannot change the temporal sequencing of events, so it cannot evaluate changes in flood timing. The quantile mapping bias-correction approach was selected here for both precipitation and PET (this method has also been referred to as distribution mapping, probability mapping, model output statistics, or histogram equalisation). The quantile mapping approach accounts for errors in the variability of PET, and ensures that heavy precipitation events important for high flows were appropriately corrected as well as mean precipitation. It also corrected for biases in the number of wet days in the RCM data.

Observed precipitation and PET data used for bias correction came from the CEH-GEAR (Keller et al., 2015; Tanguy et al., 2014) and CHESS-PE (Robinson et al., 2015) datasets respectively. For each grid-cell and month for precipitation the following steps were performed:

1. Empirical Cumulative Distribution Functions (CDFs) were calculated for the observed precipitation, and RCM simulated precipitation for the control/baseline period (all dates where observed and simulated precipitation were available).

2. The fractional change in precipitation between the observed and control/baseline simulated was calculated for each cumulative probability.

3. The whole simulated precipitation series was then bias-corrected. The cumulative probability of each precipitation value was calculated, and the value was modified by the fractional change for that cumulative probability.

The same method was carried out for PET, with a minor modification. It was found that for some Scottish catchments, fractional changes could become very large when PET values were low $(<0.1 \mathrm{~mm} /$ day $)$ as a result of dividing by values close to 0 . To prevent unrealistic spikes in future PET at low cumulative probabilities, a check was added to ensure that PET values 195 at a low cumulative probability were always smaller than values at a higher cumulative probability. This bias correction 
methodology successfully reduced biases in RCM data over the observational period (see Supplement S1 for more information). However, it is important to note that bias correction assumes that (i) despite biases in hydrometeorological variables, the RCM output is still meaningful and changes in hydrometeorological variables are well simulated, and (ii) biases in RCM output are stationary and so methods of bias correcting baseline data also hold into the future, (iii) the observed data used in bias correction is not erroneous. The quantile mapping bias correction approach is also limited because there will be few observations to constrain the $\mathrm{CDF}$ at the extreme high end of observations (e.g., exceptionally heavy rainfall events), and therefore bias correction is likely to be less robust for the rarest events

The bias-corrected RCM data was used directly as hydrological model input, with no further downscaling. This was possible due to the size of the catchments we have chosen to analyse coupled with the high resolution $(12 \mathrm{~km})$ of the RCM data, which is a key advantage of the UKCP18 climate product over previous climate projections.

\subsection{Hydrological modelling}

The DECIPHeR hydrological modelling framework was selected to transform precipitation and PET into river flows (Coxon et al., 2019). DECIPHeR is a semi-distributed hydrological modelling framework which discretises the modelling domain into hydrological response units (HRUs). Here, the model was configured to be consistent with the 12km UKCP18 data, with HRUs defined by splitting the landscape into $12 \mathrm{~km}$ input grids which were further sub-divided by accumulated area classes, slope classes and sub-catchment boundaries to capture topographic and catchment attribute controls in hydrological processes. This HRU-based approach enabled representation of the spatial variation of input time series, while being computationally efficient to facilitate the use of multiple hydrological and RCM parameter sets across the large sample of catchments. Here, we have

215 selected the default model structure, which is based on the widely used TOPMODEL, and has previously been shown to perform well across GB and selected catchments (Coxon et al., 2019; Lane et al., in review).

National fields of model parameters have been generated using the multiscale parameter regionalisation technique (Samaniego et al., 2010), as described in (Lane et al., in review.; Lane, 2021). This method relates model parameters to spatial catchment attribute data (including soil texture, land-use, and hydrogeology) via transfer functions. The coefficients of the transfer functions were then constrained simultaneously on a large sample of 437 British catchments, instead of directly constraining model parameters. Over 3500 possible parameter fields were produced, and of these, the top 30 parameter fields were selected for this study to explore the uncertainty due to model parameter selection. These parameter fields were selected as they produced non-parametric KGE scores (Pool et al., 2018) above 0.8, when taking the average value across the large sample of catchments in GB (Lane et al., in review). Using catchment attribute data to define the spatial distribution of model parameters means that parameter fields are spatially coherent with no artificial discontinuities (Mizukami et al., 2017; Samaniego et al., 2017). This is advantageous when modelling climate impacts for larger regions or entire countries, as it has been shown that artificial discontinuities in parameter fields can lead to discontinuities in modelled variables (Mizukami et al., 2017). 
230 The DECIPHeR framework requires inputs of precipitation and PET, as well as spatial catchment attribute data for parameterisation. The model was driven continuously with climate data over the period 01/01/1981 - 30/12/2075, with 01/09/1985 - 30/8/2010 extracted as the baseline period and 01/09/2050 - 30/08/2075 being used as the future period in all further analysis. Starting the baseline in 1985 gave over four years for a hydrological model warm-up period. Hydrological simulations were also carried out using observed data over the period 01/01/1981 - 30/08/2010, to provide a benchmark of model performance which the RCM-driven simulations could be compared against over the baseline. For these simulations, potential evapotranspiration data from the CHESS-PE dataset (Robinson et al., 2015) and precipitation data from CEH-GEAR (Keller et al., 2015) were re-gridded to match the UKCP18 12km data. All observed river flow data were from the UK National River Flow Archive (NRFA) (Centre for Ecology and Hydrology, 2016).

\subsection{Hydrological indicators}

240 To explore changes in the magnitude of high flows, we calculated the percentage changes in four different flow metrics between the baseline (1985-2010) and future (2050-2075) periods. Flow metrics calculated were 1) the average annual maximum (AMAX) flow, 2) Q1, the flow value exceeded $1 \%$ of the time, 3) Q10, the flow value exceeded $10 \%$ of the time, and 4) Q50, the median flow or flow value exceeded 50\% of the time. These were selected to give a broad overview of future higher flow changes, ranging from flood flows (AMAX and Q1) to average flows (Q50).

To analyse changes in the frequency of high flows, a peaks-over-threshold (POT) analysis was carried out. Thresholds were defined for each catchment to extract an average of three peaks per year over the baseline period. To ensure flood events were independent, no peak was selected within seven days of a larger peak. This selection was consistent with previous studies, for example, Svensson et al. (2005) used a five-day window for catchments smaller than 45,000 $\mathrm{km}^{2}$ (the largest catchments in the UK are $\sim 10,000 \mathrm{~km}^{2}$ ), while Petrow \& Merz, (2009) used ten days for catchments across Germany. Having found a POT threshold for each catchment over the baseline that resulted in an average of 3 peaks per year, the number of peaks exceeding this threshold in the future period was counted. The percentage change between the count of 75 peaks total gained in the baseline and peaks gained in the future was then calculated as an indication of changes in the frequency of flood events.

\section{Results}

\subsection{Meteorological changes}

Median precipitation is projected to decrease almost everywhere. GB-average median precipitation is projected to decrease by 31-61\% between the different RCMs, with the only exception being in west Scotland (Figure 3a). This decreasing median precipitation contrasts with very high precipitation $\left(99^{\text {th }}\right.$ percentile), which is expected to increase across most of GB, by an 
average of $5-20 \%$. The $90^{\text {th }}$ percentile precipitation shows a more mixed picture, with GB-average changes of $-9 \%$ to $+6 \%$. Generally, increases were simulated for areas along the west coast and in western Scotland, while decreases can be seen across southern England and Wales.

All RCMs indicate increasing PET over the modelled period (Figure 3b-c). These broadly align with observed PET across GB between 1980-2010, although it is difficult to distinguish an upward trend in the observed PET data over such a short period. GB-average PET values show increases of 23-38\% between the baseline and future period, with the largest PET increases (33$50 \%$ ) seen in the south, and the smallest PET increases (11-19\%) simulated for north-west Scotland. Note that these increases in PET are likely linked to the fact that the UKCP18 projections sample the warmer range of possible climate outcomes (Lowe et al., 2019).

\subsection{Evaluation of climate-hydrological modelling chain}

Overall, the simulations of the climate-hydrological modelling chain across GB bounded the observations (Figure 2). Our evaluation focused on the performance for hydrological indicators relevant for higher flows, namely flow quantiles Q50, Q10, and Q1 and AMAX flows. Catchments with storage reservoirs and regulated flow regimes were removed for this analysis, as these are not included in the model meaning any errors in these catchments would not be due to the driving data. The maps (Figure 2a) show biases in the highest (i.e., wettest) and lowest (i.e., driest) simulation for each individual catchment from the ensemble of 12 RCMs and 30 hydrological model parameter sets compared to observed flows. For catchments which are well represented by the modelling chain, we would expect simulated flows to bound the observations. Therefore the highest simulation would show a small positive bias, and the lowest simulation would show a small negative bias. For the majority of catchments (75\% for Q50, 64\% for Q10 and 65\% for Q1) the model simulations bound observed discharge. The model tends to underestimate AMAX flows in north-west England and Wales, and overestimate in the south-east, with only $47 \%$ of simulations bounding the observed AMAX. For at least 70\% of catchments median biases are less than 30\% for Q50, Q10 and Q1, and less than 36\% for AMAX flows. However, the modelling chain overestimated flows in the south-east across all high flow metrics. The difficulties of modelling catchments in south-east England has been documented in previous studies (Coxon et al., 2019; Lane et al., 2019; Seibert et al., 2018), and is likely due to complex aquifer systems facilitating inter-catchment groundwater flow. These catchments should, therefore, be treated with caution when interpreting the results.

Model performances are shown in more detail for a selection of catchments covering a variety of error characteristics (Figure 2b). Here, error (i.e., bias) in modelled flow driven by RCM output (green) is compared to modelled flows driven by observations (yellow) using the same 30 hydrological model parameter sets. For most gauges, simulated flows bound the observations, even when driven by the RCM meteorological data. This result was expected as the RCM data has been biascorrected against observations, and therefore the RCM data will be similar to observations in magnitude, albeit with different sequencing of events. There is no consistent relationship between model biases and flow percentiles, with gauge 9002 showing 
an increased tendency to overestimate higher flows, while gauge 83013 showed a decreased tendency to overestimate higher flows.

\subsection{Spatial changes in high flows across GB}

Maps showing the spatial pattern of changes in high flow magnitude and frequency are presented for three example simulations in Figure 4. As the spatial pattern was similar between the ensemble members, we have focused on RCMs 13, 8 and 4 which represent low, average, and high GB-average projections respectively (calculated based on GB-average Q10 changes). These projections were selected to indicate the range in flow changes across GB, but plots for a larger number of scenarios, and showing absolute changes as well as percentage changes, are given in Supplement S2. It is important to note that the maps in Figure 4 are spatially coherent futures from single RCM ensemble projections and a single hydrological model parameter set. Therefore they do not reflect the full range of flow changes for each individual catchment that would be obtained by evaluating the entire RCM ensemble driven by all hydrological model parameter sets. Plots showing the ensemble range for each catchment are therefore also given in Supplement S2.

Despite differences between the example projections, there is a clear east/west divide for high flow magnitude metrics (AMAX, Q1 and Q10) with increased flows for catchments in the west and decreasing flows in the east. The largest percentage decreases in high flows are in eastern England, particularly in the Anglian river basin district, while the largest increases in flow are along the west coast. It is important to note that the large percentage changes in flows for the south-east could be due to the low baseline flow values, so small absolute changes will result in larger percentage changes (see Supplement S2 for presentation of absolute and percentage change maps). Median flow (Q50) projections indicate reductions in flow almost everywhere, but these reductions are generally lower for catchments in western Scotland. The frequency of high flow events, represented by changes to the number of peaks over threshold events, also shows general increases in the west and reductions in the south-east. The spatial pattern is very similar to the changes to high flow magnitude, indicating that western catchments could experience larger annual maximum floods combined with more frequent high flow events.

\subsection{Regional changes and uncertainties}

Changes for the hydrological indices for the different RCMs and across regions were visualized by heatmaps to enable easy comparison (Figure 5). These heatmaps present the median flow values from the sample of hydrological model parameters for each flow statistic, with the full range of regional projections presented in Table 1. They highlight similarities between RCM members: most RCM ensembles result in increasing AMAX flows in Scotland, northern England, and west Wales, and decreasing AMAX flows in the Anglian river basin district. Most RCM ensembles also result in decreasing Q50 flows everywhere except for the Argyll and West Highland districts in west Scotland. However, there are also important differences between the different RCM projections, including; i) differences in the spatial variation of changes across GB, for example 
RCM 15 shows relatively little variation between regions (range of $28 \%$ between AMAX projections) while RCM 11 shows a large variation (range of 104\%), ii) differences in the magnitude of projected changes for each region, for example NW England projections for Q10 range from $-16 \%$ to $+20 \%$ between RCMs, and iii) the tendency for some RCMs to simulate increases in flow (e.g., RCM 04) while others tend towards decreases (e.g., RCM 13) which relates to relative change in $99^{\text {th }}$ percentile precipitation (see Figure 3). These differences demonstrate the importance of considering multiple RCMs, to show a more complete picture of potential future changes.

RCM parameters were a larger source of uncertainty in flow changes than hydrological model parameters (see Figure 6). This finding agrees with previous studies, which generally find climate models to be the largest source of uncertainty in hydrological climate impact assessments (Addor et al., 2014; Bosshard et al., 2013; Kay et al., 2009). However, hydrological model parameters selection is a large source of uncertainty in the south-east, especially in the Anglian river basin region. This region receives relatively little precipitation compared to the rest of GB. Previous studies have shown that drier catchments are more sensitive to parameter selection, with fewer good parameter sets for drier than for wet catchments (Lane et al., 2019). It is however possible that high percentage differences in the south-east are due to the lower river flow values magnifying the percentage value of any changes.

\subsection{Relationship between climate changes, flow changes and catchment characteristics}

The relationship between precipitation change and change in flood flows (Q1) across all catchments, and RCMs is presented in Figure 7. This shows that there is a strong positive correlation between precipitation change and flood response, albeit with a large variation between catchments. The non- linearity between changing precipitation and changing Q1 flows can be seen, with a $25 \%$ increase in precipitation leading to a $20-50 \%$ increase in Q1. Surprisingly, for some catchments, heavy precipitation increases yet there is a reduction in Q1 flows (i.e., catchments in the bottom right quadrant of Figure 7). This flow reduction could be due to the contrasting effect of increasing PET, resulting in generally drier anticedent conditions for catchments and thus reduced flows due to the increases in soil moisture storage deficits.

The relationship between change in $95^{\text {th }}$ percentile precipitation, total PET and Q1 is given in Figure 8; other variations of precipitation, PET and flow changes produced similar results (but are not shown). There is a clear relationship between climate forcing and hydrological response. Increased heavy precipitation tends to lead to increased Q1, while decreased or unchanged heavy precipitation, combined with increasing PET, leads to reduced Q1 flows. The range in climatic changes is different for each region (see Figure 8b), which is a key reason for the regional differences in Q1 changes. However, the hydrological response differed between regions for the same climate forcing. For example, a $6 \%$ decrease in $95^{\text {th }}$ percentile precipitation 355 and over 45\% increase in total PET leads to an average 53\% reduction in Q1 in the Anglian river basin district, but only an average 15\% decrease in Q1 in the Thames region in the South-east. These results highlight the importance of how multiple climatic factors impact regional flow responses differently due to the non-linearity within the hydrological processes. 
The observed runoff coefficient (runoff divided by precipitation) helped to explain these regional differences in catchment

flow response to climatic change inputs. Figure 9 shows the relationship between $95^{\text {th }}$ precipitation, PET and Q1 changes, with catchments grouped by Runoff Coefficient classes. Catchments with relatively low runoff coefficients tend to show a higher sensitivity to the increasing PET. They are therefore more likely to see decreasing Q1 flows even with small $(<5 \%)$ increases in heavy precipitation. These catchments are often drier catchments, and so heavy precipitation events may fill storage deficits rather than result in increased river flow. Other catchment properties, such as deep soils or permeable geology may also contribute to water being retained in the catchment. By contrast, catchments with high runoff coefficients show more sensitivity to changes in heavy precipitation, and very small (5\%) increases in precipitation can lead to increases in Q1 of up to $25 \%$. These are often wetter catchments, or catchments with other properties such as steep slopes or impermeable soils, where increases in heavy rainfall will directly result in increases in flood flows.

\section{Discussion}

\subsection{Future changes to high flows across GB}

Despite large uncertainties, some clear patterns of climate change impact on flooding across GB emerged. Projections indicated decreasing median flows (Q50) across all regions except for the Clyde and West Highland river basin regions where Q50 changes ranged between $-42 \%$ to $+19 \%$. The overall decrease in Q50 was likely due to reduced average precipitation and nationwide increases in PET projected by all the RCMs.

Increased flood flow magnitudes (AMAX) and frequency were projected for all RCMs along the west coast (excluding the south-west) and across most of Scotland, while decreasing flood flows were projected for the Anglian river basin region in east England using the median of all hydrological model parameter sets. These results are consistent with Collet et al. (2018), who found that hydro-hazard hotspots were likely to develop along the west coast and north-eastern Scotland. Kay et al. (2014) also modelled large increases to flood peaks in north-west Scotland. However, our results contrast with Bell et al. (2016) and Kay, et al. (2014), which both found relatively large increases in flood flows in the south-east and Anglian in particular. This contrast could be due to the different metric studied (Bell et al. (2016) and Kay, et al. (2014) both showed percentage changes in 20-year return period floods, while we show changes in AMAX floods), or other methodological differences such as hydrological model or climate projections. However, we found hydrological modelling studies to be particularly large for the

385 Anglian region and therefore increases in AMAX flows were within the total uncertainty range of a $-74 \%$ to $+19 \%$ change, in line with these previous studies.

Our modelled changes in AMAX and high flow magnitudes (Table 1) will be useful to inform climate change adaptation, for example in ensuring correct allowances are made for changing fluvial flood risk in new developments. To account for the 

flood risk throughout their lifetime by applying an allowance for the potential impact of climate change (Reynard et al., 2017). These have evolved from a simple $20 \%$ allowance applied nationally, to a range of allowances for each river basin district that represent the central $\left(50^{\text {th }}\right.$ percentile), the higher central $\left(70^{\text {th }}\right.$ percentile), the upper end $\left(90^{\text {th }}\right.$ percentile) and the $\mathrm{H}++$ (highest) projections of changes to peak river flows (Environment Agency, 2020a). Our highest regional projections are within the H++ government allowances for southern and central England, but our highest projections exceed the government H++ peak flow allowances for northern England (Solway, Tweed, Northumbria and North-west England river basin districts). In particular, the H++ allowance for peak flow changes in the Tweed river basin is 35\% for the 2050s (Environment Agency, 2020a), but our projections include peak flow changes of up to 59\%. Therefore, our projections indicate that current guidance could be underestimating the potential risks from climate change for northern England. However, the use of different time-periods (we modelled changes by 2050-2075 whereas the government allowances cover the period 2040-2069) restricts the comparability of these results.

\subsection{Relationship between climate changes and hydrological response}

It is often assumed that increases in extreme precipitation will lead to increases in flood flows (Sharma et al., 2018). However, while there is observational evidence of increasing precipitation extremes, there is no compelling evidence for any systematic increases in flooding which can be attributed to climate change (Hannaford, 2015; Watts et al., 2015). Understanding the link between changing precipitation and changing floods has, therefore, been highlighted as an important challenge for the hydrologic community (Sharma et al., 2018). Here we found that while there was a strong positive relationship between changes in heavy precipitation (as characterised by changes in the $95^{\text {th }}$ percentile precipitation) and changes in high flows (Q1), there were catchments where precipitation was increasing yet modelled flood flows were decreasing. These catchments

410 were found to have large increases in PET - and therefore the impact of drier soils and increased storage deficits could have moderated the impact of increased heavy precipitation on river flows.

We found that the relationship between changes in heavy precipitation, total PET and changes to flood flows varied between river basin regions. The catchment runoff coefficient (average river flow divided by average precipitation) helped to explain this variation; for catchments with high runoff coefficients precipitation increases most directly related to increased flood

415 flows, while catchments with low runoff coefficients showed a greater response to increasing PET. This in part relates to previous studies finding that there is a more direct link between heavy rainfall and high flows in wetter catchments (Charlton and Arnell, 2014; Ivancic and Shaw, 2015), as there is a general relationship between the runoff coefficient and catchment wetness. It's important to realise that the interplay between general runoff co-efficients of different catchment typologies and the amount they are impacted by changes in both evaporation and precipitation to Q1 high flow sensitivity is not consistent, as shown in Figure 9. Therefore we recognise that impacts to high flows are multifaceted and the uniqueness of catchment characteristics and climatological differences needs to be taken into account when quantifying climate change impacts. This 
result highlights that it is important to recognise the complexities of flow change resulting from multiple climatic drivers and non-linear hydrological processes.

\subsection{Uncertainties in climate impacts on high flows}

Our results highlight the importance of considering uncertainty in projections of climate change on flood flows. The selection of RCM parameters impacted not only the range of future changes for each region (often disagreeing on the direction of change), but also variation in changes between regions, and to some extent the spatial pattern of changes across GB. This, combined with hydrological modelling uncertainties, resulted in the large ranges in future changes given in Table 1. The selection of metrics used to explore climate impacts was a further source of uncertainty; the picture of climate change impacts on flows differed between the four metrics presented here. The incorporation of multiple uncertainty sources, therefore, prevents an overconfident portrayal of climate change impacts on high flows, which could be misleading if used to inform future planning or policy decisions (Buurman and Babovic, 2016; Kundzewicz et al., 2018).

Previous studies found hydrological modelling uncertainties to be small relative to climate modelling uncertainties, especially when considering high flows (Chen et al., 2011; Velázquez et al., 2013). Our results generally support these findings, showing that the variation in future changes between RCMs is much larger than the variation between behavioural hydrological model parameter sets. However, we observed substantial hydrological modelling uncertainties for catchments in England, particularly for the Anglian river basin and drier catchments in the south-east. It is likely that interactions between the RCMs and hydrological model parameters also contribute to the total uncertainty where behaviour is not linear. For example, the AMAX variation between different hydrological model parameter sets may depend on the winter rainfall projection from the driving RCM, where certain RCM projections may lie on a threshold which produces a large difference in hydrological response between models. It has previously been shown that interactions between uncertainty sources can account for 5-40\% of the total uncertainty in hydrological climate change impacts studies (Bosshard et al., 2013). This emphasized that while uncertainties in future climate may dominate, uncertainties due to hydrological model parameters are not negligible.

There are many uncertainty sources that we were not able to incorporate. In addition to RCM and hydrological model parameters, sources of uncertainty in hydrological climate impact studies include the structure and parameterisation of the global climate model (GCM), bias correction methods, PE estimation equation, and hydrological model structure (Bosshard et al., 2013; Kay et al., 2009; Prudhomme and Davies, 2009; Wilby and Harris, 2006). The RCM ensemble projections applied 450 here were all driven by the same GCM and emissions scenario, and so do not sample the full range of climate uncertainty. Therefore, while our results provide a useful indication of the range in future changes to high flow metrics across GB the true uncertainty ranges are likely to be much larger. 
A further limitation of this study is that the hydrological modelling framework did not include snow accumulation and melt

processes. However, snow fractions are generally very low across GB, with a median snow fraction of 0.01 , except for catchments in north-east Scotland where it reaches a maximum of 0.17 (Coxon et al., 2020). The impact of including a snow module on climate change projections for peak flows was investigated by Bell et al. (2016). They found that across most of GB the inclusion of a snowmelt regime led to small percentage differences in peak flow changes of less than $6 \%$. However, snowmelt processes were shown to be important for upland parts of GB, mainly in East Scotland, where the reduced presence of snow in the future could have a large impact on river flows. Therefore, the results of our study need to be interpreted with caution in these upland catchments.

\section{Conclusions}

In this study we modelled climate change impact on the magnitude and frequency of high flows across 346 catchments in GB, considering both RCM and hydrological model parameter uncertainties for the first time at the national scale. The latest UK Climate Projections (UKCP18) were used to generate 12 spatially coherent and equally plausible time-series of precipitation and PET. These were then used to drive the DECIPHeR hydrological modelling framework, using 30 nationally consistent parameter fields. The resultant 360 future flow projections were used to investigate the range of changes in high flow magnitude and frequency between baseline (1985 - 2010) and future (2050 - 2075) scenarios, as well as the relationship between climatic change and hydrological response.

Generally, results indicated increasing magnitude and frequency of flood flows for catchments along the west coast of GB, and across most of Scotland. For western Scotland, region-average increases in annual maximum flows of up to $65 \%$ were projected. The Anglian and Thames river basins in eastern England generally showed decreasing flood magnitude and frequency. However, hydrological modelling uncertainty was high for these areas and therefore increases in flood magnitude 475 were also within the ensemble range.

Regional differences in high flow changes were related to i) differences in climatic change signals and ii) differences in catchment conditions during the baseline period as characterised by the runoff coefficient (total discharge/precipitation). A strong relationship was found between increasing heavy precipitation and increasing flood flows, alongside the moderating impact of increased PET. This relationship differed between catchments; catchments with high runoff coefficients were found to have a more direct response of flood flows to precipitation change, while catchments with low runoff coefficients were more responsive to increased PET often resulting in very large reductions in Q1 flows (-50\%) in areas with small (-5\%) reductions in $95^{\text {th }}$ percentile precipitation. 
485 Our results highlight the importance of considering uncertainties in climate impact studies. The variation between RCMs was the largest source of uncertainty, with differences in both the magnitude of projected changes for individual regions and the variability between regions. Hydrological modelling uncertainties were smaller, but still considerable for catchments in east and south-east England.

490 This paper provides a national overview of projected future changes in median and higher flows across GB, with the full ensemble range in projected changes given for each region. This information will be useful for decision-makers who have a role in managing or planning water in GB, for example in water companies, regulators and government.

Author contribution

495 RL, JF, GC, JS and TW were involved in the project conceptualization and design of methodology. RL, GC and JF were involved in the data curation. RL and GC setup the DECIPHeR model to run using UKCP18 data. RL carried out the model parameterisation, model runs, data analysis, visualisation and writing with comments and edits from all co-authors.

\section{Acknowledgements}

500 We would like to acknowledge Emma Robinson for providing code used to calculate PET for the CHESS-PE dataset, and for her advice in applying this to the UKCP18 data. We would also like to thank Louise Slater and Jeff Neal for their helpful comments on the manuscript. This work is funded as part of the Water Informatics Science and Engineering Centre for Doctoral Training (WISE CDT) under a grant from the Engineering and Physical Sciences Research Council (EPSRC; grant number EP/L016214/1). Jim Freer was partly funded for his time by the Global Water Futures program, University of Saskatchewan.

505 Support for Thorsten Wagener comes from the Alexander von Humboldt Foundation in the framework of the Alexander von Humboldt Professorship endowed by the German Federal Ministry of Education and Research.

\section{Code availability}

The DECIPHeR model code is open-source and freely available under the terms of the GNU General Public License version 510 3.0. The model code is written in Fortran and is provided through a Github repository: https:/github.com/uob-hydrology/ DECIPHeR. Code for the model parameterisation is available to view at http://doi.org/10.5281/zenodo.4646179.

\section{Data availability}

All precipitation, PET and discharge datasets used in this study are freely available. The CEH-GEAR and CHESS-PE datasets

515 are freely available from CEH's Environmental Information Data Centre and can be accessed through https://doi.org/10.5285/ 5dc179dc-f692-49ba-9326-a6893a503f6e (Tanguy et al., 2014) and https://doi.org/10.5285/8baf805d-39ce-4dac-b224c926ada353b7 (Robinson et al., 2015a) respectively. Observed discharge data from the NRFA are available from the NRFA website. The UK Climate Projections data is available to download from the CEDA Archive (Met Office Hadley Centre, 2020). 
Model outputs presented in this paper unfortunately cannot be made open access due to license restrictions on the datasets used to parameterise the model.

Competing interests

The authors declare that they have no conflict of interest.

\section{References}

Addor, N. and Seibert, J.: Bias correction for hydrological impact studies - beyond the daily perspective, Hydrol. Process., 28(17), 4823-4828, doi:10.1002/hyp.10238, 2014.

530 Addor, N., Rössler, O., Köplin, N., Huss, M., Weingartner, R. and Seibert, J.: Robust changes and sources of uncertainty in the projected hydrological regimes of Swiss catchments, Water Resour. Res., 50(10), 7541-7562, doi:10.1002/2014WR015549, 2014.

Arnell, N. W.: Uncertainty in the relationship between climate forcing and hydrological response in UK catchments, Hydrol. Earth Syst. Sci., doi:10.5194/hess-15-897-2011, 2011.

535 Bell, V. A., Kay, A. L., Jones, R. G. and Moore, R. J.: Use of a grid-based hydrological model and regional climate model outputs to assess changing flood risk, Int. J. Climatol., 27, 1657-1671, doi:10.1002/joc.1539, 2007.

Bell, V. A., Kay, A. L., Cole, S. J., Jones, R. G., Moore, R. J. and Reynard, N. S.: How might climate change affect river flows across the Thames Basin? An area-wide analysis using the UKCP09 Regional Climate Model ensemble, J. Hydrol., 442-443, 89-104, doi:10.1016/j.jhydrol.2012.04.001, 2012.

540 Bell, V. A., Kay, A. L., Davies, H. N. and Jones, R. G.: An assessment of the possible impacts of climate change on snow and peak river flows across Britain, Clim. Change, doi:10.1007/s10584-016-1637-x, 2016.

Bosshard, T., Carambia, M., Goergen, K., Kotlarski, S., Krahe, P., Zappa, M. and Schar, C.: Quantifying uncertainty sources in an ensemble of hydrological climate-impact projections, Water Resour. Res., 49(3), 1523-1536, doi:10.1029/2011WR011533, 2013.

545 Brown, C. M., Lund, J. R., Cai, X., Reed, P. M., Zagona, E. A., Ostfeld, A., Hall, J., Characklis, G. W., Yu, W. and Brekke, L.: The future of water resources systems analysis: Toward a scientific framework for sustainable water management, Water Resour. Res., doi:10.1002/2015WR017114, 2015.

Buurman, J. and Babovic, V.: Adaptation Pathways and Real Options Analysis: An approach to deep uncertainty in climate change adaptation policies, Policy Soc., doi:10.1016/j.polsoc.2016.05.002, 2016.

550 Centre for Ecology and Hydrology: National River Flow Archive, [online] Available from: http://nrfa.ceh.ac.uk/ (Accessed 23 
January 2017), 2016.

Charlton, M. B. and Arnell, N. W.: Assessing the impacts of climate change on river flows in England using the UKCP09 climate change projections, J. Hydrol., 519(PB), 1723-1738, doi:10.1016/j.jhydrol.2014.09.008, 2014.

Chen, J., Brissette, F. P., Poulin, A. and Leconte, R.: Overall uncertainty study of the hydrological impacts of climate change for a Canadian watershed, Water Resour. Res., doi:10.1029/2011WR010602, 2011.

Christierson, B. v., Vidal, J.-P. and Wade, S. D.: Using UKCP09 probabilistic climate information for UK water resource planning, J. Hydrol., 424-425, 48-67, doi:10.1016/j.jhydrol.2011.12.020, 2012.

Clark, M. P., Wilby, R. L., Gutmann, E. D., Vano, J. A., Gangopadhyay, S., Wood, A. W., Fowler, H. J., Prudhomme, C., Arnold, J. A. and Brekke, L. D.: Characterizing uncertainty of the hydrologic impacts of climate change, Curr. Clim. Chang.

Reports, 55-64, doi:10.1007/s40641-016-0034-x, 2016.

Cloke, H. L., Wetterhall, F., He, Y., Freer, J. E. and Pappenberger, F.: Modelling climate impact on floods with ensemble climate projections, Q. J. R. Meteorol. Soc., 139(671), 282-297, doi:10.1002/qj.1998, 2013.

Collet, L., Harrigan, S., Prudhomme, C., Formetta, G. and Beevers, L.: Future hot-spots for hydro-hazards in Great Britain: A probabilistic assessment, Hydrol. Earth Syst. Sci., doi:10.5194/hess-22-5387-2018, 2018.

565 Coxon, G., Freer, J., Lane, R., Dunne, T., Knoben, W. J. M., Howden, N. J. K., Quinn, N., Wagener, T. and Woods, R.: DECIPHeR v1: Dynamic fluxEs and ConnectIvity for Predictions of HydRology, Geosci. Model Dev., doi:10.5194/gmd-122285-2019, 2019.

Coxon, G., Addor, N., Bloomfield, J., Freer, J., Fry, M., Hannaford, J., Howden, N., Lane, R., Lewis, M., Robinson, E., Wagener, T. and Woods, R.: CAMELS-GB: Hydrometeorological time series and landscape attributes for 671 catchments in Great Britain, Earth Syst. Sci. Data, doi:10.5194/essd-2020-49, 2020.

Dixon, H., Hannaford, J. and Fry, M. J.: The effective management of national hydrometric data: experiences from the United Kingdom, Hydrol. Sci. J., doi:10.1080/02626667.2013.787486, 2013.

Eicker, A., Forootan, E., Springer, A., Longuevergne, L. and Kusche, J.: Does GRACE see the terrestrial water cycle “intensifying”?, J. Geophys. Res., doi:10.1002/2015JD023808, 2016.

575 Engin, B. E., Yücel, I. and Yilmaz, A.: Assessing different sources of uncertainty in hydrological projections of high and low flows: case study for Omerli Basin, Istanbul, Turkey, Environ. Monit. Assess., doi:10.1007/s10661-017-6059-3, 2017.

Environment Agency: Flood risk assessments: climate change allowances' Guidance, [online] Available from: https://www.gov.uk/guidance/flood-risk-assessments-climate-change-allowances (Accessed 25 November 2020a), 2020.

Environment Agency: National Flood and Coastal Erosion Risk Management Strategy for England., 2020b.

580 Fowler, H. J. and Ekström, M.: Multi-model ensemble estimates of climate change impacts on UK seasonal precipitation extremes, Int. J. Climatol., 29(3), 385-416, doi:10.1002/joc.1827, 2009.

Hannaford, J.: Climate-driven changes in UK river flows: A review of the evidence, Prog. Phys. Geogr., 39(1), 29-48, doi:10.1177/0309133314536755, 2015.

Huntington, T. G.: Evidence for intensification of the global water cycle: Review and synthesis, J. Hydrol., 319, 83-95, 
doi:10.1016/j.jhydrol.2005.07.003, 2006.

IPCC: Climate Change 2013 - The Physical Science Basis, edited by Intergovernmental Panel on Climate Change, Cambridge University Press, Cambridge., 2014.

Ivancic, T. J. and Shaw, S. B.: Examining why trends in very heavy precipitation should not be mistaken for trends in very high river discharge, Clim. Change, doi:10.1007/s10584-015-1476-1, 2015.

590 Kay, A. L. and Crooks, S. M.: An investigation of the effect of transient climate change on snowmelt, flood frequency and timing in northern Britain, Int. J. Climatol., doi:10.1002/joc.3913, 2014.

Kay, A. L. and Davies, H. N.: Calculating potential evaporation from climate model data: A source of uncertainty for hydrological climate change impacts, J. Hydrol., doi:10.1016/j.jhydrol.2008.06.005, 2008.

Kay, A. L., Davies, H. N., Bell, V. A. and Jones, R. G.: Comparison of uncertainty sources for climate change impacts: Flood 595 frequency in England, Clim. Change, doi:10.1007/s10584-008-9471-4, 2009.

Kay, A. L., Crooks, S. M., Davies, H. N., Prudhomme, C. and Reynard, N. S.: Probabilistic impacts of climate change on flood frequency using response surfaces I: England and Wales, Reg. Environ. Chang., 14(3), 1215-1227, doi:10.1007/s10113-0130563-y, 2014a.

Kay, A. L., Crooks, S. M., Davies, H. N. and Reynard, N. S.: Probabilistic impacts of climate change on flood frequency using 600 response surfaces II: Scotland, Reg. Environ. Chang., 14(3), 1243-1255, doi:10.1007/s10113-013-0564-X, 2014b.

Kay, A. L., Watts, G., Wells, S. C. and Allen, S.: The impact of climate change on U. K. river flows: A preliminary comparison of two generations of probabilistic climate projections, Hydrol. Process., 34(4), 1081-1088, doi:10.1002/hyp.13644, 2020.

Keller, V. D. J. J., Tanguy, M., Prosdocimi, I., Terry, J. A., Hitt, O., Cole, S. J., Fry, M., Morris, D. G. and Dixon, H.: CEHGEAR : $1 \mathrm{~km}$ resolution daily and monthly areal rainfall estimates for the UK for hydrological and other applications, Earth

605 Syst. Sci. Data, 7, 143-155, doi:10.5194/essd-7-143-2015, 2015.

Köplin, N., Schädler, B., Viviroli, D. and Weingartner, R.: Seasonality and magnitude of floods in Switzerland under future climate change, Hydrol. Process., doi:10.1002/hyp.9757, 2014.

Kundzewicz, Z. W., Krysanova, V., Benestad, R. E., Hov, Piniewski, M. and Otto, I. M.: Uncertainty in climate change impacts on water resources, Environ. Sci. Policy, doi:10.1016/j.envsci.2017.10.008, 2018.

610 Laizé, C. L. R. and Hannah, D. M.: Modification of climate-river flow associations by basin properties, J. Hydrol., 389(1-2), 186-204, doi:10.1016/j.jhydrol.2010.05.048, 2010.

Lane, R., Coxon, G., Freer, J., Wagener, T., Johnes, P., Bloomfield, J., Greene, S., Macleod, C. and Reaney, S.: Benchmarking the predictive capability of hydrological models for river flow and flood peak predictions across over 1000 catchments in Great Britain, Hydrol. Earth Syst. Sci., doi:10.5194/hess-23-4011-2019, 2019.

615 Lane, R., Freer, J., Coxon, G. and Wagener, T.: Incorporating uncertainty into multiscale parameter regionalisation to produce national parameter fields for a hydrological model, n.d.

Lane, R. A.: National-scale hydrological modelling of high flows across Great Britain: multi-model structures, regionalisation approaches and climate change analysis with uncertainty, University of Bristol. [online] Available from: https://research- 
information.bris.ac.uk/en/studentTheses/national-scale-hydrological-modelling-of-high-flows-across-great-, 2021.

Lane, R. A. and Kay, A. L.: Climate change impact on the magnitude and timing of hydrological extremes across Great Britain, Front. Water, n.d.

Lowe, J. A., Bernie, D., Bett, P., Bricheno, L., Brown, S., Calvert, D., Clark, R., Eagle, K., Edwards, T., Fosser, G., Fung, F., Gohar, L., Good, P., Gregory, J., Harris, G., Howard, T., Kaye, N., Kendon, E., Krijnen, J., Maisey, P., McDonald, R., McInnes, R., McSweeney, C., Mitchell, J., Murphy, J., Palmer, M., Roberts, C., Rostron, J., Sexton, D., Thornton, H., Tinker, J., Tucker, S., Yamazaki, K. and Belcher, S.: UKCP18 Science Overview Report: Version 2.0. [online] Available from: https://www.metoffice.gov.uk/pub/data/weather/uk/ukcp18/science-reports/UKCP18-Overview-report.pdf, 2019.

Mendoza, P. A., Clark, M. P., Mizukami, N., Newman, A. J., Barlage, M., Gutmann, E. D., Rasmussen, R. M., Rajagopalan, B., Brekke, L. D. and Arnold, J. R.: Effects of Hydrologic Model Choice and Calibration on the Portrayal of Climate Change Impacts, J. Hydrometeorol., 16(2), 762-780, doi:10.1175/JHM-D-14-0104.1, 2015.

Meresa, H. K. and Romanowicz, R. J.: The critical role of uncertainty in projections of hydrological extremes, Hydrol. Earth Syst. Sci., doi:10.5194/hess-21-4245-2017, 2017.

Met Office: UK Climate Projections: Headline Findings. [online] Available from: https://www.metoffice.gov.uk/binaries/content/assets/metofficegovuk/pdf/research/ukcp/ukcp-headline-findings-v2.pdf, 2019.

635 Met Office: Regional (12km) and Local $(2.2 \mathrm{~km})$ Projections, [online] Available from: https://www.metoffice.gov.uk/research/approach/collaboration/ukcp/high-res-projections (Accessed 30 June 2020), 2020. Met Office Hadley Centre: UKCP18 Guidance: Data availability, access and formats. [online] Available from: https://www.metoffice.gov.uk/binaries/content/assets/metofficegovuk/pdf/research/ukcp/ukcp18-guidance-data-availabilityaccess-and-formats.pdf, 2019.

640 Mizukami, N., Clark, M. P., Newman, A. J., Wood, A. W., Gutmann, E. D., Nijssen, B., Rakovec, O. and Samaniego, L.: Towards seamless large-domain parameter estimation for hydrologic models, Water Resour. Res., 53(9), 8020-8040, doi:10.1002/2017WR020401, 2017.

Murphy, J. M., Harris, G. R., Sexton, D. M. H., Kendon, E. J., Bett, P. E., Clark, R. T., Eagle, K. E., Fosser, G., Fung, F., Lowe, J. A., McDonald, R. E., McInnes, R. N., McSweeney, C. F., Mitchell, J. F. B., Rostron, J. W., Thornton, H. E., Tucker, 645 S., Yamazaki, K. and Murphy: UKCP18 Land Projections: Science Report. [online] Available from: https://www.metoffice.gov.uk/pub/data/weather/uk/ukcp18/science-reports/UKCP18-Land-report.pdf, 2018.

De Niel, J., Van Uytven, E. and Willems, P.: Uncertainty Analysis of Climate Change Impact on River Flow Extremes Based on a Large Multi-Model Ensemble, Water Resour. Manag., doi:10.1007/s11269-019-02370-0, 2019.

Nikulin, G., Kjellström, E., Hansson, U., Strandberg, G. and Ullerstig, A.: Evaluation and future projections of temperature, 650 precipitation and wind extremes over Europe in an ensemble of regional climate simulations, Tellus, Ser. A Dyn. Meteorol. Oceanogr., doi:10.1111/j.1600-0870.2010.00466.x, 2011.

Ning, L., Mann, M. E., Crane, R. and Wagener, T.: Probabilistic projections of climate change for the mid-Atlantic region of 
the United States: Validation of precipitation downscaling during the historical era, J. Clim., doi:10.1175/2011JCLI4091.1, 2012.

655 Petrow, T. and Merz, B.: Trends in flood magnitude, frequency and seasonality in Germany in the period 1951-2002, J. Hydrol., doi:10.1016/j.jhydrol.2009.03.024, 2009.

Pool, S., Vis, M. and Seibert, J.: Evaluating model performance: towards a non-parametric variant of the Kling-Gupta efficiency, Hydrol. Sci. J., doi:10.1080/02626667.2018.1552002, 2018.

Prudhomme, C. and Davies, H.: Assessing uncertainties in climate change impact analyses on the river flow regimes in the UK. Part 2: Future climate, Clim. Change, doi:10.1007/s10584-008-9461-6, 2009.

Prudhomme, C. and Williamson, J.: Derivation of RCM-driven potential evapotranspiration for hydrological climate change impact analysis in Great Britain: A comparison of methods and associated uncertainty in future projections, Hydrol. Earth Syst. Sci., doi:10.5194/hess-17-1365-2013, 2013.

Prudhomme, C., Young, A., Watts, G., Haxton, T., Crooks, S., Williamson, J., Davies, H., Dadson, S. and Allen, S.: The drying up of Britain? A national estimate of changes in seasonal river flows from 11 Regional Climate Model simulations, Hydrol. Process., 26(7), 1115-1118, doi:10.1002/hyp.8434, 2012.

Reynard, N. S., Kay, A. L., Anderson, M., Donovan, B. and Duckworth, C.: The evolution of climate change guidance for fluvial flood risk management in England, Prog. Phys. Geogr., doi:10.1177/0309133317702566, 2017.

Robinson, E., Blyth, E., Clark, D., Finch, J. and Rudd, A.: Climate hydrology and ecology research support system potential evapotranspiration dataset for Great Britain (1961-2012) [CHESS-PE]., 2015.

Rudd, A. C., Kay, A. L. and Bell, V. A.: National-scale analysis of future river flow and soil moisture droughts: potential changes in drought characteristics, Clim. Change, 156(3), 323-340, doi:10.1007/s10584-019-02528-0, 2019.

Samaniego, L., Kumar, R. and Attinger, S.: Multiscale parameter regionalization of a grid-based hydrologic model at the mesoscale, Water Resour. Res., 46(5), 1-25, doi:10.1029/2008WR007327, 2010.

675 Samaniego, L., Kumar, R., Thober, S., Rakovec, O., Zink, M., Wanders, N., Eisner, S., Müller Schmied, H., Sutanudjaja, E., Warrach-Sagi, K. and Attinger, S.: Toward seamless hydrologic predictions across spatial scales, Hydrol. Earth Syst. Sci., 21(9), 4323-4346, doi:10.5194/hess-21-4323-2017, 2017.

Sawicz, K. A., Kelleher, C., Wagener, T., Troch, P., Sivapalan, M. and Carrillo, G.: Characterizing hydrologic change through catchment classification, Hydrol. Earth Syst. Sci., doi:10.5194/hess-18-273-2014, 2014.

680 Seibert, J., Vis, M. J. P., Lewis, E. and van Meerveld, H. J.: Upper and lower benchmarks in hydrological modelling, Hydrol. Process., 32(8), 1120-1125, doi:10.1002/hyp.11476, 2018.

Sharma, A., Wasko, C. and Lettenmaier, D. P.: If Precipitation Extremes Are Increasing, Why Aren't Floods?, Water Resour. Res., doi:10.1029/2018WR023749, 2018.

Shuttleworth, W. J.: Terrestrial Hydrometeorology, John Wiley \& Sons, Ltd, Chichester, UK., 2012.

685 Singh, R., van Werkhoven, K. and Wagener, T.: Hydrological impacts of climate change in gauged and ungauged watersheds of the Olifants basin: a trading-space-for-time approach, Hydrol. Sci. J., doi:10.1080/02626667.2013.819431, 2014. 
Smith, A., Bates, P., Freer, J. and Wetterhall, F.: Investigating the application of climate models in flood projection across the UK, Hydrol. Process., 28(5), 2810-2823, doi:10.1002/hyp.9815, 2014.

Svensson, C., Kundzewicz, Z. W. and Maurer, T.: Trend detection in river flow series: 2. Flood and low-flow index series, Hydrol. Sci. J., doi:10.1623/hysj.2005.50.5.811, 2005.

Tanguy, M., Dixon, H., Prosdocimi, I., Morris, D. and Keller, V. D. J.: Gridded estimates of daily and monthly areal rainfall for the United Kingdom (1890-2012) [CEH-GEAR]. [online] Available from: https://doi.org/10.5285/5dc179dc-f692-49ba9326-a6893a503f6e, 2014.

Teutschbein, C. and Seibert, J.: Bias correction of regional climate model simulations for hydrological climate-change impact studies: Review and evaluation of different methods, J. Hydrol., 456-457, 12-29, doi:10.1016/j.jhydrol.2012.05.052, 2012. Thober, S., Kumar, R., Wanders, N., Marx, A., Pan, M., Rakovec, O., Samaniego, L., Sheffield, J., Wood, E. F. and Zink, M.: Multi-model ensemble projections of European river floods and high flows at 1.5, 2, and 3 degrees global warming, Environ. Res. Lett., doi:10.1088/1748-9326/aa9e35, 2018.

Trenberth, K.: Changes in precipitation with climate change, Clim. Res., 47(1), 123-138, doi:10.3354/cr00953, 2011.

Veijalainen, N., Lotsari, E., Alho, P., Vehviläinen, B. and Käyhkö, J.: National scale assessment of climate change impacts on flooding in Finland, J. Hydrol., doi:10.1016/j.jhydrol.2010.07.035, 2010.

Velázquez, J. A., Schmid, J., Ricard, S., Muerth, M. J., Gauvin St-Denis, B., Minville, M., Chaumont, D., Caya, D., Ludwig, R. and Turcotte, R.: An ensemble approach to assess hydrological models' contribution to uncertainties in the analysis of climate change impact on water resources, Hydrol. Earth Syst. Sci., 17(2), 565-578, doi:10.5194/hess-17-565-2013, 2013.

705 Wagener, T., Sivapalan, M., Troch, P. A., McGlynn, B. L., Harman, C. J., Gupta, H. V., Kumar, P., Rao, P. S. C., Basu, N. B. and Wilson, J. S.: The future of hydrology: An evolving science for a changing world, Water Resour. Res., 46(5), 1-10, doi:10.1029/2009WR008906, 2010.

Wang, G. Q., Zhang, J. Y., Jin, J. L., Pagano, T. C., Calow, R., Bao, Z. X., Liu, C. S., Liu, Y. L. and Yan, X. L.: Assessing water resources in China using PRECIS projections and a VIC model, Hydrol. Earth Syst. Sci., doi:10.5194/hess-16-231-2012, 2012.

Watts, G., Battarbee, R. W., Bloomfield, J. P., Crossman, J., Daccache, A., Durance, I., Elliott, J. A., Garner, G., Hannaford, J., Hannah, D. M., Hess, T., Jackson, C. R., Kay, A. L., Kernan, M., Knox, J., Mackay, J., Monteith, D. T., Ormerod, S. J., Rance, J., Stuart, M. E., Wade, A. J., Wade, S. D., Weatherhead, K., Whitehead, P. G. and Wilby, R. L.: Climate change and water in the UK - past changes and future prospects, Prog. Phys. Geogr. Earth Environ., 39(1), 6-28, 715 doi:10.1177/0309133314542957, 2015.

Wilby, R. L. and Harris, I.: A framework for assessing uncertainties in climate change impacts: Low-flow scenarios for the River Thames, UK, Water Resour. Res., 42(2), 1-10, doi:10.1029/2005WR004065, 2006. 
https://doi.org/10.5194/hess-2021-321

Preprint. Discussion started: 29 June 2021

(c) Author(s) 2021. CC BY 4.0 License.

Hydrology and

\section{Figures}

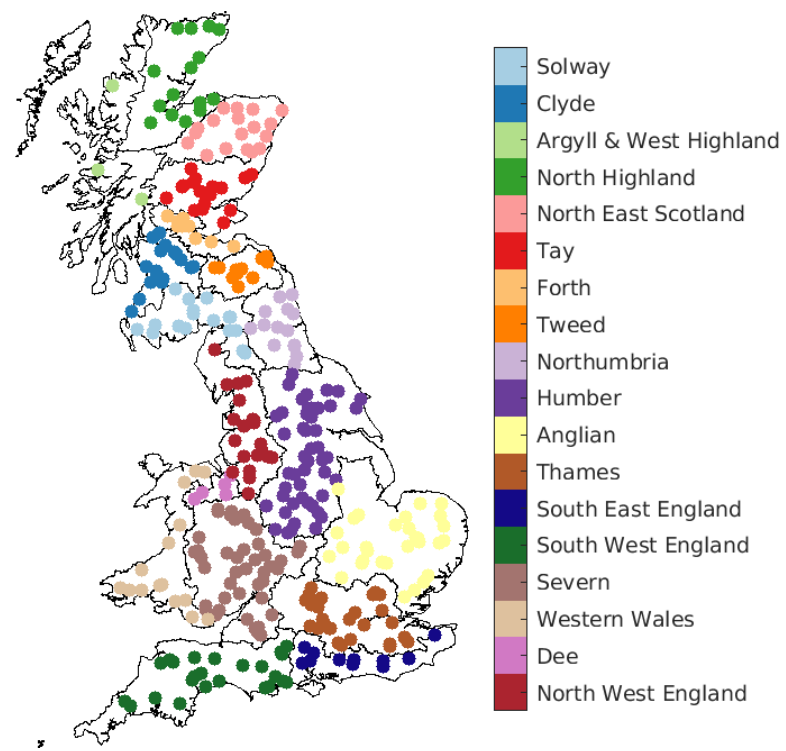

Figure 1: Locations of the catchments used in this study, grouped according to the so-called 'river basin districts'. 

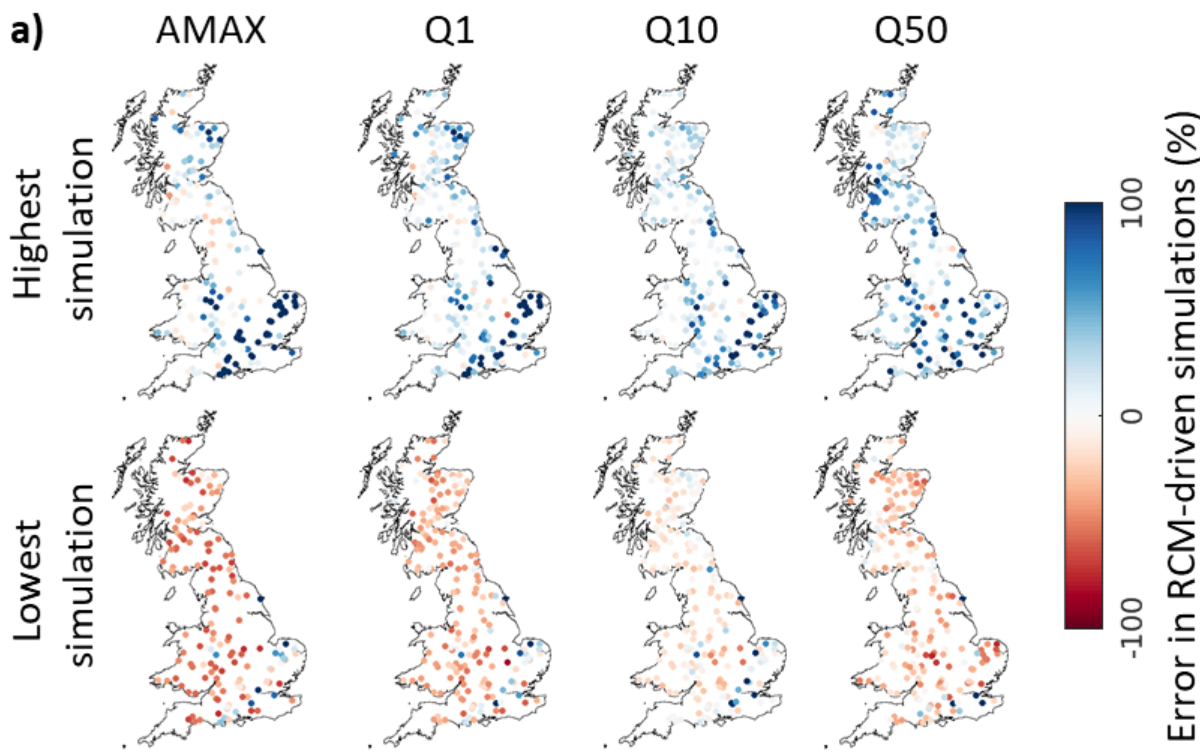

b)
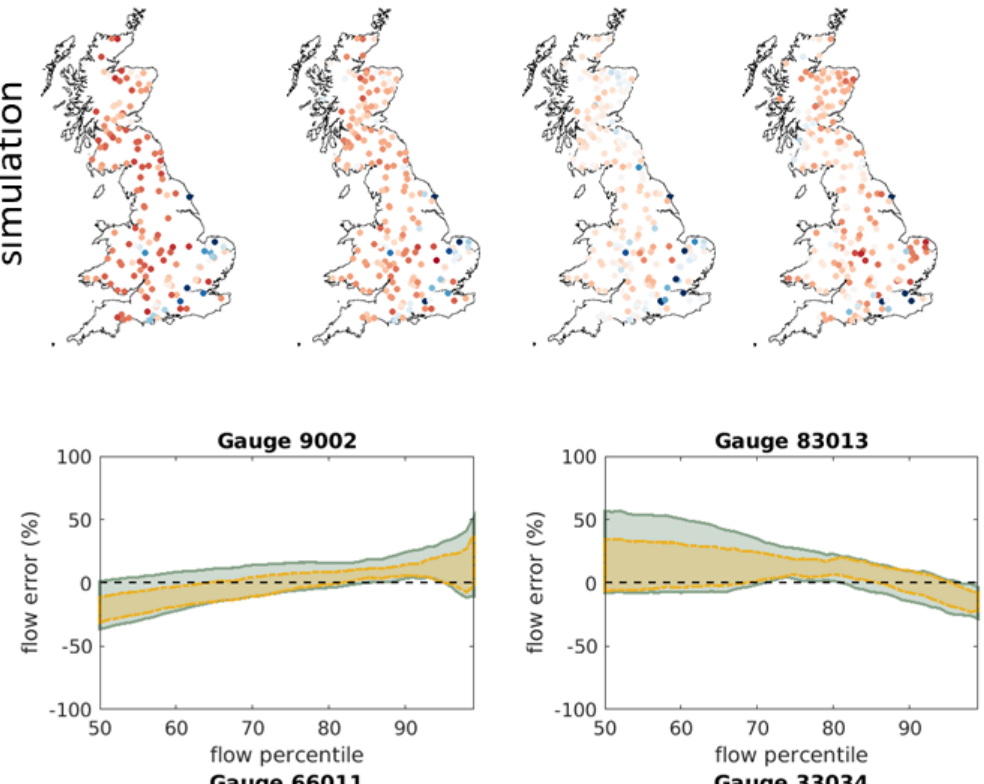

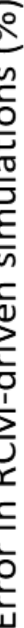
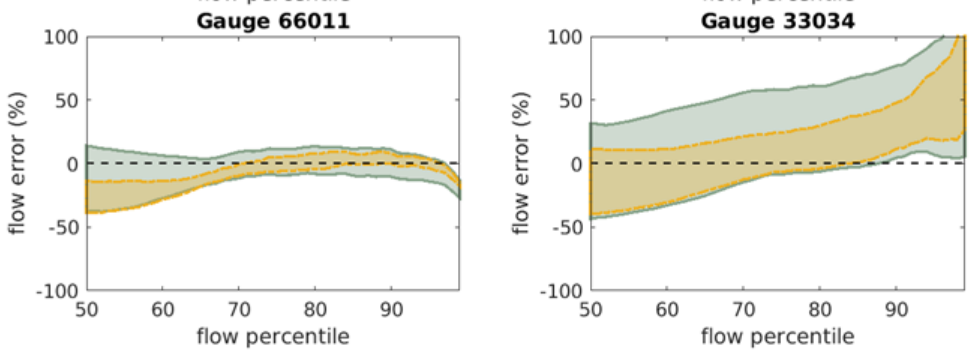

RCM-driven

simulations

Observation-driven simulations

Figure 2: Evaluation of model performance, showing how well the modelled flow statistics from the climate-hydrological cascade bound the observed flow statistics over the baseline period. The maps (a) show error in RCM-driven simulations compared to the observed. The top row shows the highest positive error from the 360 simulations, while the bottom row shows the lowest negative error, calculated separately for each catchment. When considered together, these show how well the RCM-driven simulations bound the observed flows. Four gauges are shown in more detail (b), giving error across median and higher flow percentiles compared to observations, showing both simulations driven by observations and simulations driven by RCM data. 
https://doi.org/10.5194/hess-2021-321

Preprint. Discussion started: 29 June 2021

(c) Author(s) 2021. CC BY 4.0 License.
Hydrology and

Earth System

Sciences

Discussions

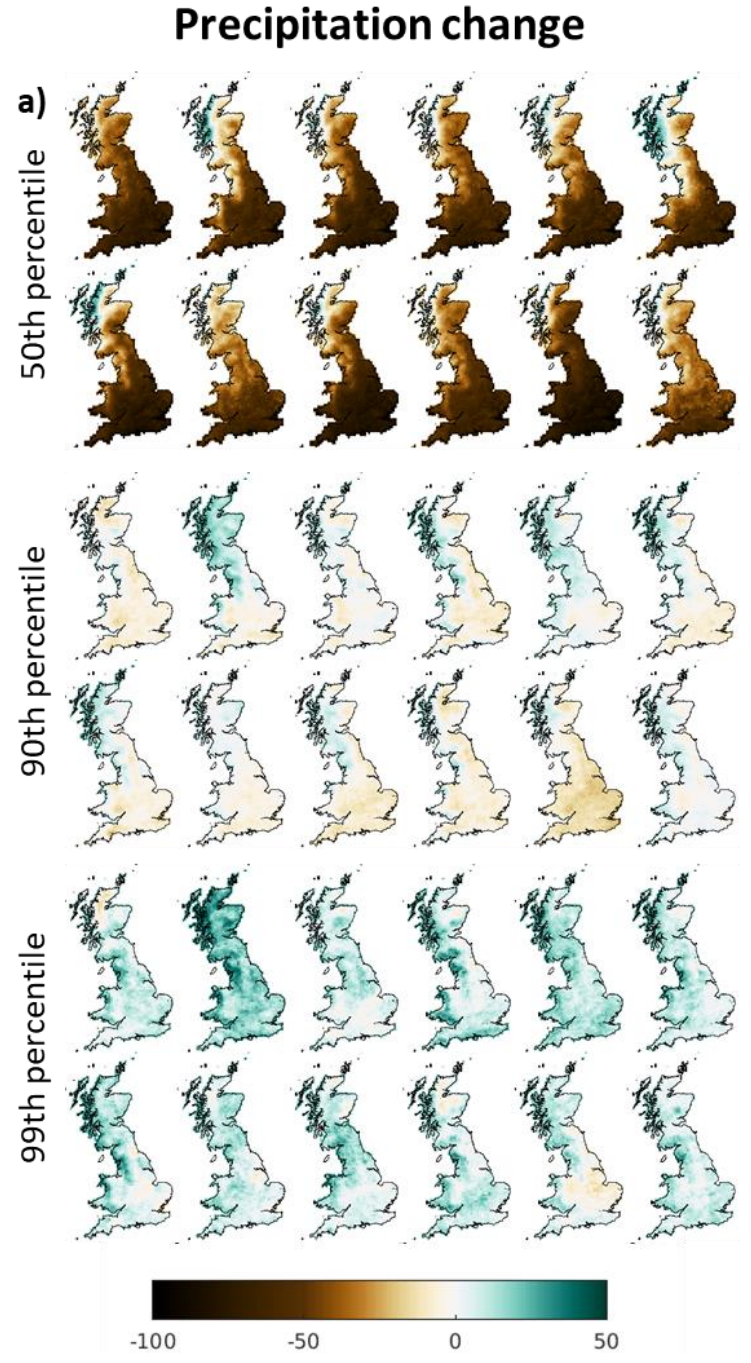

Change in precipitation percentiles

(\%)
PET change
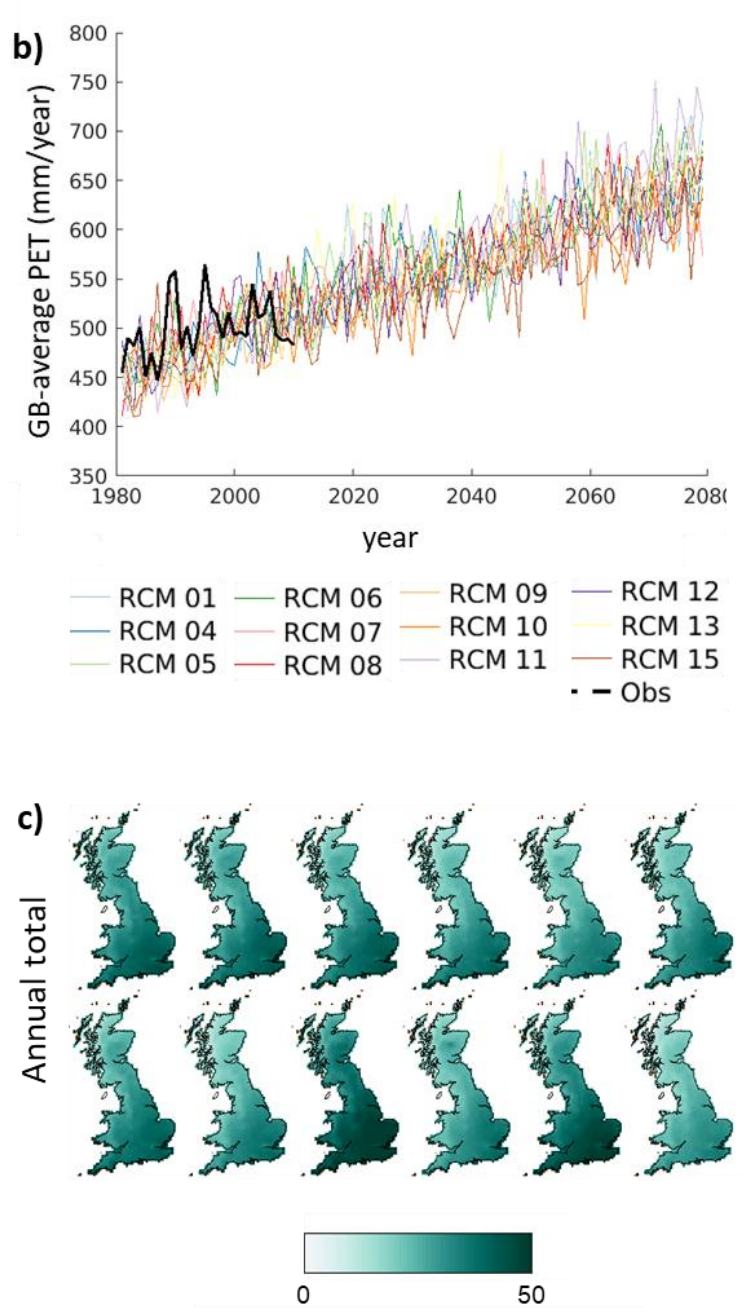

Change in annual total PET

(\%)

Figure 3: precipitation (a) and PET (b-c) change. GB-maps are presented for each ensemble member in order. Top row: RCM01,

RCM04, RCM05, RCM06, RCM07 and RCM08, bottom row: RCM09, RCM10, RCM11, RCM12, RCM13, RCM15. 


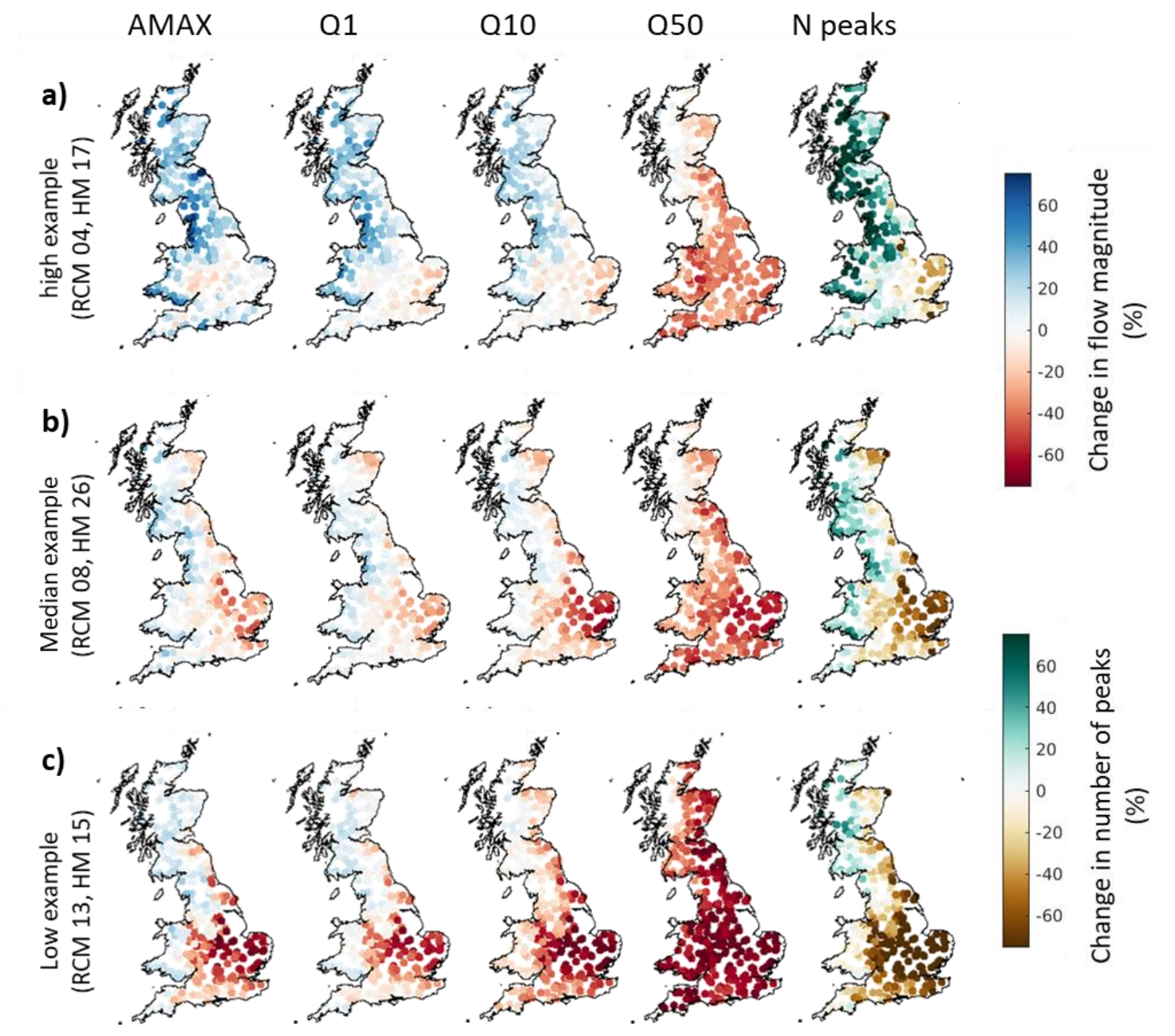

740 Figure 4: Maps showing changes in the magnitude and frequency of peak flows between the baseline and future periods for example simulations. Each row shows a nationally coherent projection, with plots of changes in five flow metrics (AMAX, Q1, Q10, Q50 and the number of peak flows above a threshold). This combination of RCMs and hydrological parameter sets were selected from the ensemble of 360 simulations to give an indication of the ensemble spread, as they provided the highest, median, and lowest GBaverage change in Q10, but they do not show the full range of possible changes for individual catchments or all flow metrics. 
https://doi.org/10.5194/hess-2021-321

Preprint. Discussion started: 29 June 2021

(c) Author(s) 2021. CC BY 4.0 License.

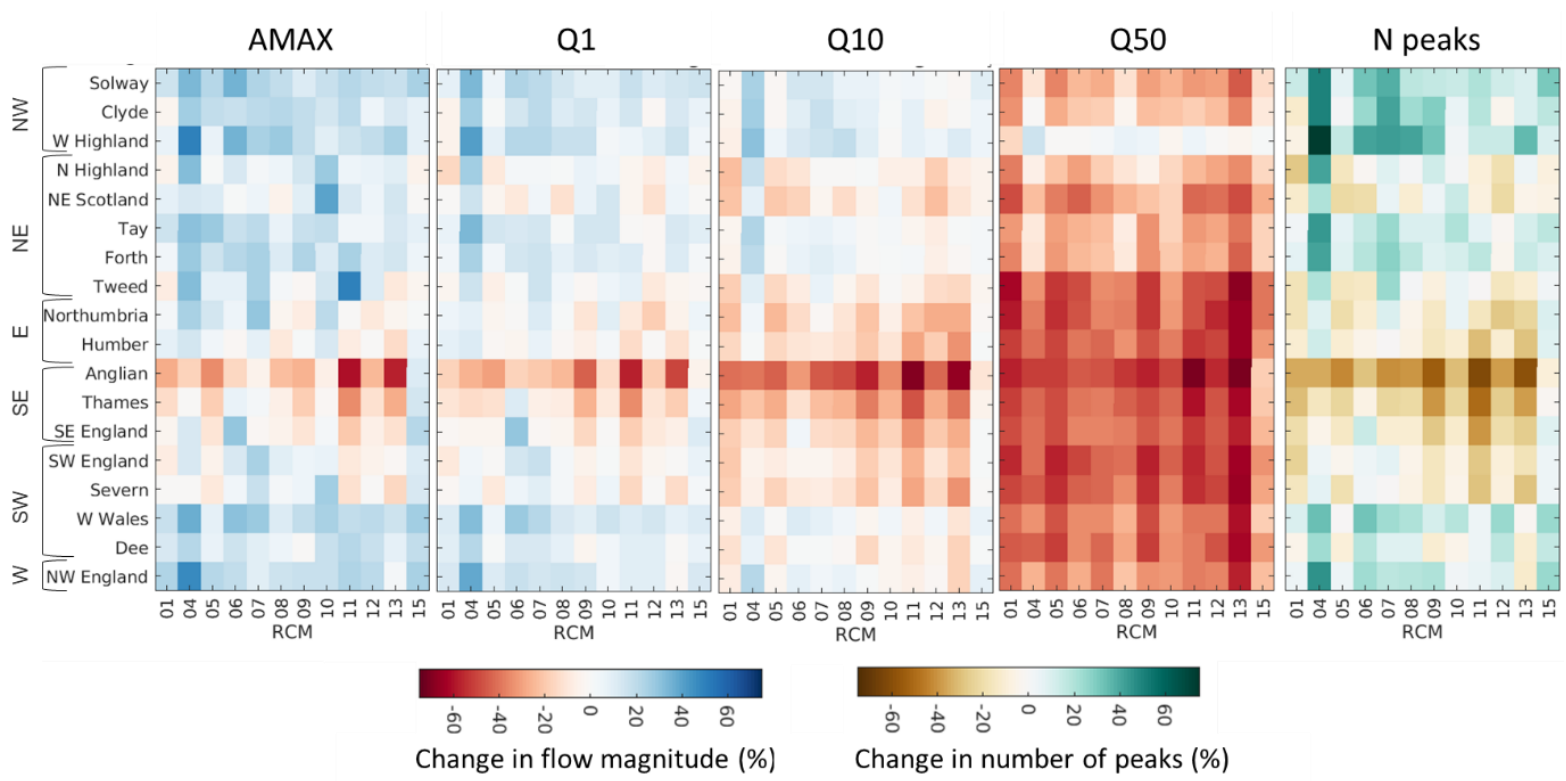

Figure 5: Heatmaps showing region-average changes in flow magnitude between the baseline and future periods, for all $12 \mathrm{RCMs.}$

Regions have been ordered by location, with the relative position within GB given on the left. To focus on differences between RCMs, the median flow value from the hydrological model parameter sets is presented.
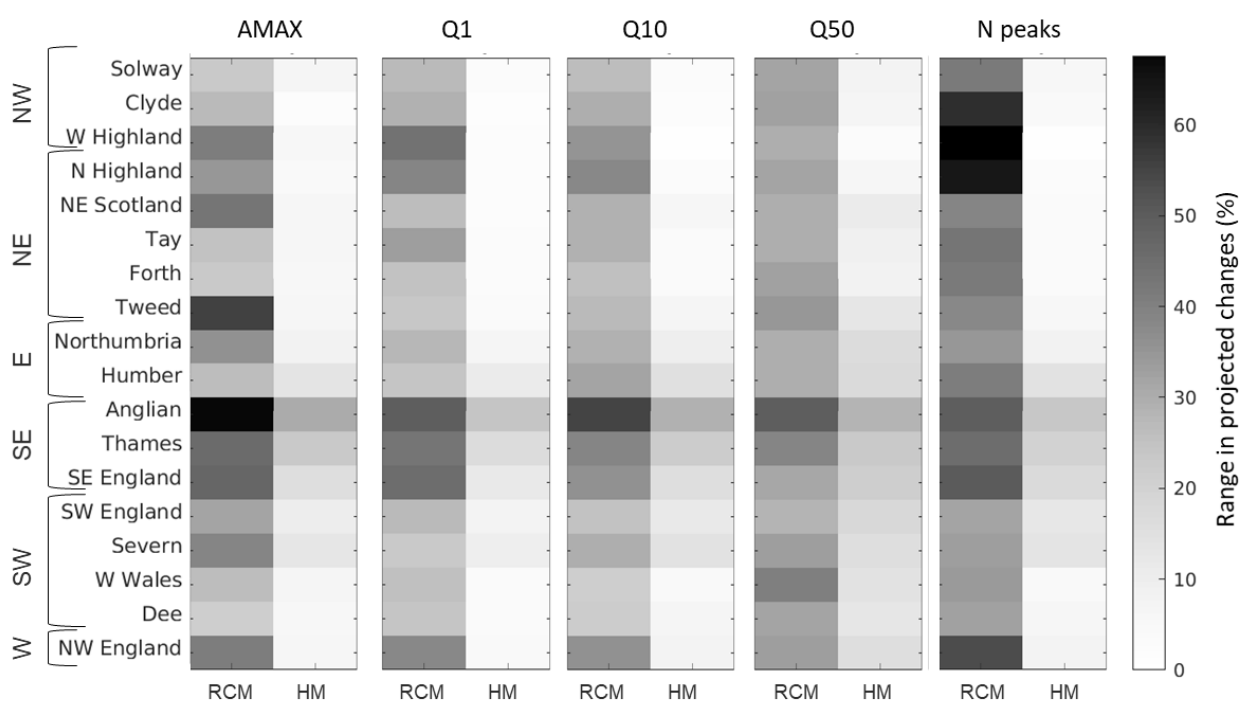

Figure 6: Relative uncertainties from inclusion of different RCM and hydrological model (HM) parameter sets. The RCM range was calculated as the full range in regional-average changes between the RCMs, using the median of all HM parameter sets. Similarly, the HM range was calculated using the median output of all RCMs. 
https://doi.org/10.5194/hess-2021-321

Preprint. Discussion started: 29 June 2021

(C) Author(s) 2021. CC BY 4.0 License.

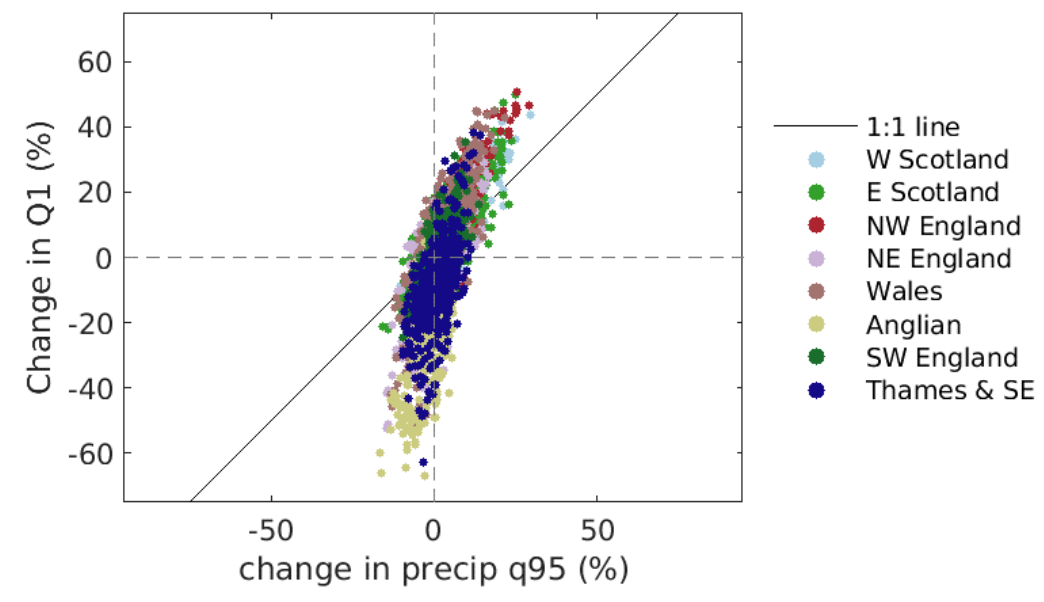

Figure 7: Relationship between precipitation change and Q1 change across all catchments. Results are presented for all RCMs using the median of all hydrological parameter sets. 
https://doi.org/10.5194/hess-2021-321

Preprint. Discussion started: 29 June 2021

(c) Author(s) 2021. CC BY 4.0 License.

a)

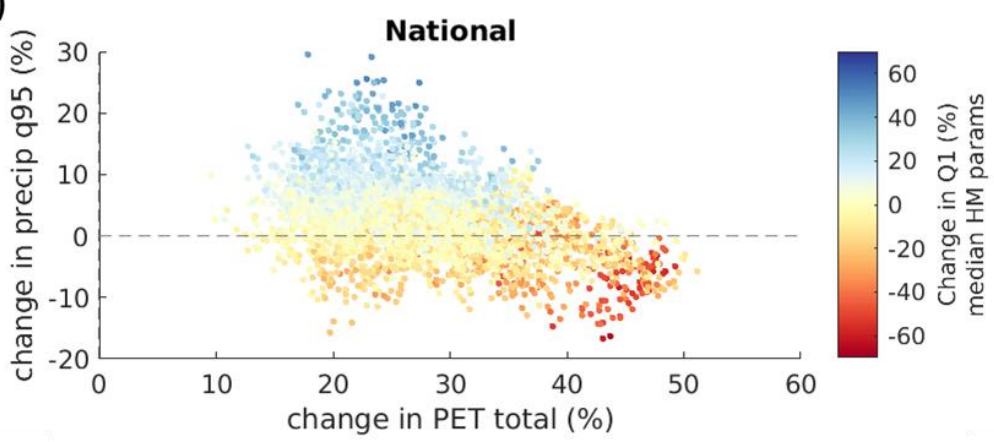

b)
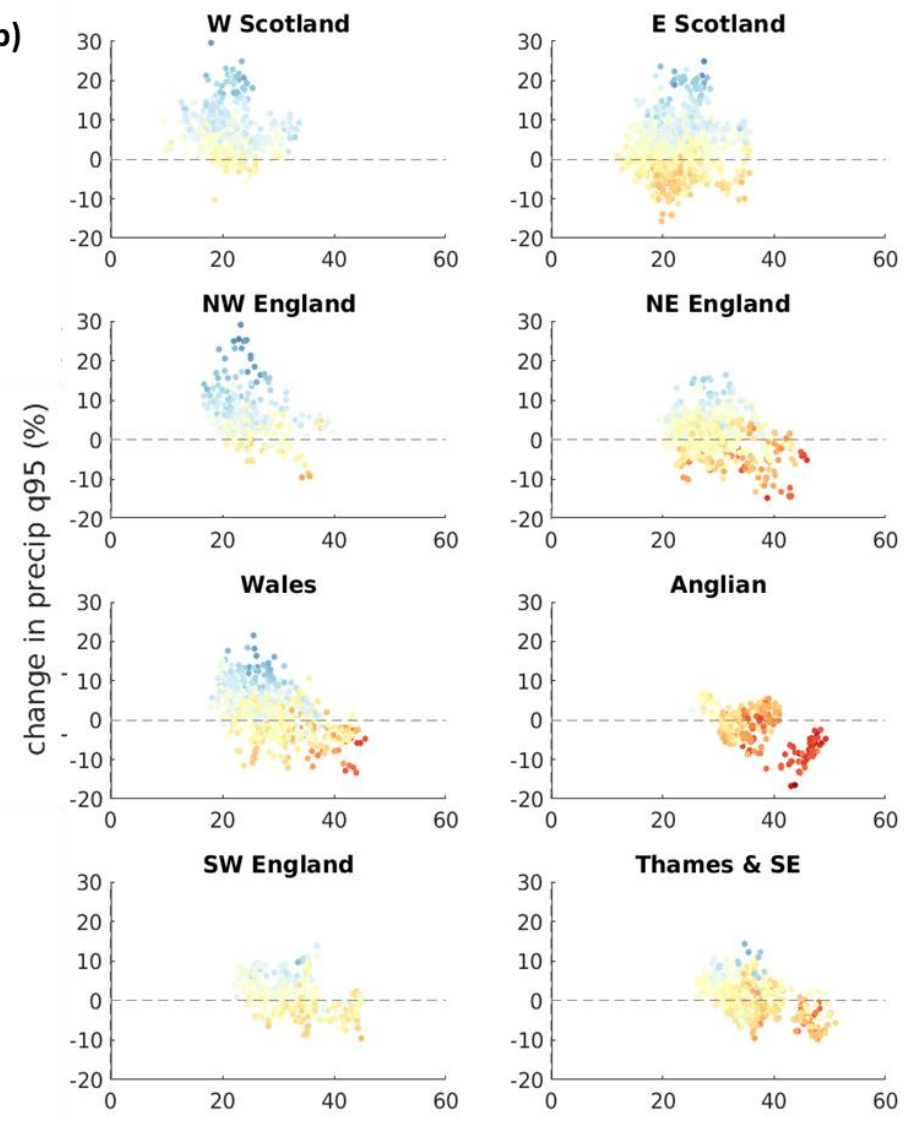

change in PET total (\%)

Figure 8: Relationship between changing climate and changing high flows (Q1), shown for all catchments nationally (a) and by region (b). Plots show climatic changes from all RCMs, coloured by the median change in Q1 flows from the ensemble of hydrological model parameter sets. Regions which are shown together, exhibited similar patterns. 
https://doi.org/10.5194/hess-2021-321

Preprint. Discussion started: 29 June 2021

(c) Author(s) 2021. CC BY 4.0 License.

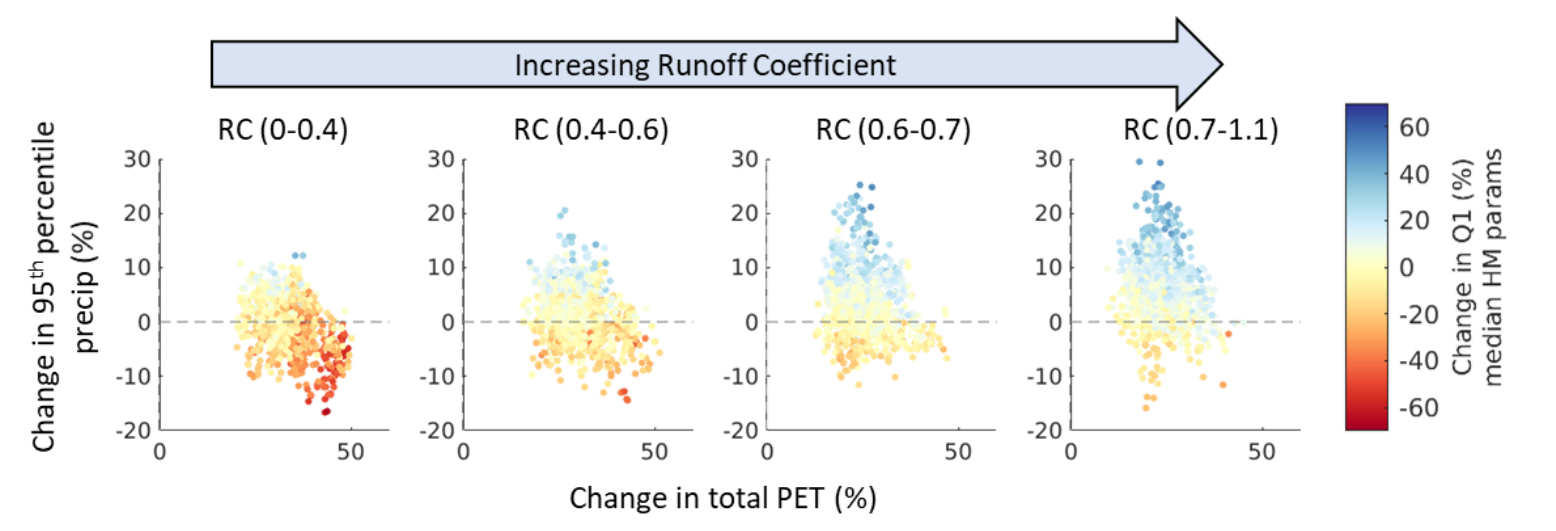

Figure 9: Runoff Coefficient (runoff divided by precipitation) vs flow sensitivity to climatic changes. 


\section{Tables}

Table 1: Ensemble range in projected changes for each flow metric. All changes are given as percentage differences between the baseline and future periods. Low, Med and High refer to the lowest, median, and highest region-average changes from the ensemble of RCM and hydrological model parameters.

\begin{tabular}{|c|c|c|c|c|c|c|c|c|c|c|c|c|c|c|c|}
\hline \multirow{2}{*}{$\begin{array}{r}\text { Region } \\
\text { Solway }\end{array}$} & \multicolumn{3}{|c|}{$\begin{array}{c}\text { AMAX change } \\
\qquad \%) \\
\text { Low, Med, High }\end{array}$} & \multicolumn{3}{|c|}{$\begin{array}{c}\text { Q1 change }(\%) \\
\text { Low, Med, } \\
\text { High }\end{array}$} & \multicolumn{3}{|c|}{$\begin{array}{c}\text { Q10 change }(\%) \\
\text { Low, Med, } \\
\text { High }\end{array}$} & \multicolumn{3}{|c|}{$\begin{array}{c}\text { Q50 change (\%) } \\
\text { Low, Med, } \\
\text { High }\end{array}$} & \multicolumn{3}{|c|}{$\begin{array}{c}\text { N. peaks change (\%) } \\
\text { Low, Med, High }\end{array}$} \\
\hline & 7 & 18 & 49 & 1 & 13 & 37 & -4 & 4 & 24 & -49 & -26 & -4 & 4 & 24 & 79 \\
\hline Clyde & -10 & 15 & 29 & -9 & 11 & 27 & -8 & 5 & 28 & -42 & -20 & 5 & -28 & 23 & 77 \\
\hline W Highland & 3 & 18 & 65 & -7 & 14 & 46 & -4 & 9 & 31 & -17 & 1 & 19 & -16 & 35 & 113 \\
\hline N Highland & -15 & 4 & 39 & -17 & -1 & 33 & -27 & -6 & 18 & -41 & -20 & 0 & -41 & -5 & 68 \\
\hline NE Scotland & -7 & 8 & 45 & -15 & 0 & 19 & -27 & -13 & 9 & -56 & -33 & -12 & -41 & -12 & 33 \\
\hline Tay & 1 & 13 & 36 & -3 & 11 & 36 & -9 & 2 & 25 & -43 & -26 & -3 & -7 & 17 & 75 \\
\hline Forth & 6 & 17 & 40 & 1 & 11 & 37 & -5 & 3 & 22 & -49 & -23 & -3 & -5 & 23 & 73 \\
\hline Tweed & -14 & 6 & 59 & -14 & 1 & 19 & -20 & -5 & 14 & -69 & -41 & -19 & -37 & -3 & 52 \\
\hline Northumbria & -11 & 3 & 38 & -20 & 2 & 17 & -32 & -16 & 8 & -69 & -44 & -24 & -39 & -16 & 26 \\
\hline Humber & -21 & 4 & 27 & -18 & 0 & 17 & -33 & -11 & 9 & -71 & -42 & -23 & -53 & -12 & 31 \\
\hline Anglian & -74 & -21 & 19 & -68 & -22 & 8 & -80 & -41 & 3 & -85 & -50 & -9 & -99 & -55 & 13 \\
\hline Thames & -50 & -10 & 15 & -44 & -10 & 18 & -59 & -24 & 4 & -72 & -41 & -11 & -78 & -34 & 16 \\
\hline SE England & -30 & -3 & 37 & -26 & -2 & 32 & -38 & -15 & 13 & -64 & -40 & -7 & -64 & -20 & 32 \\
\hline SW England & -18 & 5 & 29 & -18 & 1 & 20 & -32 & -10 & 5 & -70 & -47 & -22 & -49 & -10 & 21 \\
\hline Severn & -25 & 0 & 26 & -20 & 0 & 16 & -39 & -11 & 6 & -68 & -43 & -21 & -55 & -13 & 19 \\
\hline W Wales & 3 & 21 & 42 & 3 & 12 & 36 & -14 & 4 & 15 & -67 & -35 & -12 & -9 & 25 & 59 \\
\hline Dee & -6 & 13 & 26 & -7 & 8 & 25 & -21 & -4 & 10 & -62 & -38 & -21 & -25 & 6 & 39 \\
\hline NW England & -1 & 18 & 57 & -4 & 13 & 48 & -18 & 2 & 29 & -71 & -33 & -15 & -21 & 24 & 76 \\
\hline
\end{tabular}

